\title{
Inhibition of testicular embryonal carcinoma cell tumorigenicity by peroxisome proliferator-activated receptor- $\beta / \delta$ - and retinoic acid receptor-dependent mechanisms
}

\author{
Pei-Li Yao ${ }^{1}$, Li Ping Chen ${ }^{1}$, Tomasz P. Dobrzański ${ }^{1}$, Dylan A. Phillips ${ }^{1}$, Bokai Zhu ${ }^{1}$, \\ Boo-Hyon Kang ${ }^{2}$, Frank J. Gonzalez ${ }^{3}$, Jeffrey M. Peters ${ }^{1}$ \\ ${ }^{1}$ Department of Veterinary and Biomedical Sciences, The Center of Molecular Toxicology and Carcinogenesis, The Pennsylvania \\ State University, University Park, Pennsylvania, USA \\ ${ }^{2}$ Chemon Nonclinical Research Institute, Nampyeong-ro, Yangji-myeon, Cheoin-gu, Yongin-si, Gyeonggi-do, Korea \\ ${ }^{3}$ Laboratory of Metabolism, National Cancer Institute, Bethesda, Maryland, USA \\ Correspondence to: \\ Jeffrey M. Peters, e-mail: jmp21@psu.edu \\ Pei-Li Yao, e-mail: pxy11@psu.edu \\ Keywords: peroxisome proliferator-activated receptor- $\beta / \delta$, testicular embryonal carcinoma, retinoic acid receptor, matrix \\ metalloproteinase-2, tumorigenicity \\ Received: July 06, $2015 \quad$ Accepted: September 15, $2015 \quad$ Published: September 26, 2015
}

\section{ABSTRACT}

Peroxisome proliferator-activated receptor- $\beta / \delta(P P A R \beta / \delta)$ has important physiological functions in control of cell growth, lipid and glucose homeostasis, differentiation and inflammation. To investigate the role of PPAR $\beta / \delta$ in cancer, stable human testicular embryonal carcinoma cell lines were developed that constitutively express PPAR $\beta / \delta$. Expression of PPAR $\beta / \delta$ caused enhanced activation of the receptor, and this significantly decreased proliferation, migration, invasion, anchorage-independent growth, and also reduced tumor mass and volume of ectopic xenografts derived from NT2/D1 cells compared to controls. The changes observed in xenografts were associated with decreased PPAR $\beta / \delta$-dependent expression of proliferating cell nuclear antigen and octamer-binding transcription factor-3/4, suggesting suppressed tumor proliferation and induction of differentiation. Inhibition of migration and invasion was mediated by PPAR $\beta / \delta$ competing with formation of the retinoic acid receptor (RAR)/retinoid $X$ receptor ( $R X R$ ) complex, resulting in attenuation of RARa-dependent matrix metalloproteinase- 2 expression and activity. These results demonstrate that PPAR $\beta / \delta$ mediates attenuation of human testicular embryonal carcinoma cell progression through a novel RAR-dependent mechanism and suggest that activation of PPAR $/ \delta$ inhibits RAR/RXR dimerization and represents a new therapeutic strategy.

\section{INTRODUCTION}

Testicular germ cell tumors are prevalent in men 1540 years of age with genetic heterogeneity [1]. Although high cure rates have been achieved due to early detection and chemotherapy, the mechanisms of tumorigenesis remain elusive and there is continued need to identify novel targets that will allow for more effective prevention and treatment of this disease with reduced side effects [2-4]. Embryonal carcinoma is the most common component of mixed testicular germ cell tumors, which are difficult to diagnose, and are highly metastatic [5]. Moreover, testicular cancer is associated with other common testicular disorders, including impaired spermatogenesis, cryptorchidism and hypospadias, that likely arise from shared mechanisms [6]. Thus, there is a pressing need to gain new insights into the mechanisms and etiology of testicular cancer development, in particular embryonal carcinomas.

Peroxisome proliferator-activated receptor- $\beta / \delta$ $(\operatorname{PPAR} \beta / \delta)$ is a ligand activated transcription factor that actively regulates gene expression through multiple 
mechanisms [7]. PPAR $\beta / \delta$ and its heterodimerization partner retinoid $\mathrm{X}$ receptor (RXR) dynamically bind as a complex to response elements on chromatin after interacting with other proteins such as co-repressors, co-activators, and endogenous agonists [7]. Binding of PPAR $\beta / \delta / R X R$ regulates the expression of a broad range of genes and controls numerous biological processes, including cell differentiation and proliferation, lipid and glucose homeostasis, and inflammation [8]. Interestingly, the relative expression levels and/or presence (or absence) of intra-nuclear co-repressors, co-activators, endogenous agonists, and RXR can influence the activities of nuclear receptors including PPARs, retinoic acid receptors (RARs), thyroid hormone receptor and vitamin D receptor [9-11]. Thus, there are multiple levels of regulation that can impact nuclear receptor-mediated signaling due to competition for the availability of similar co-factors required for an active heterodimerized transcription factor including PPAR $\beta / \delta[7,12-14]$.

Previous studies showed that over-expression and/ or ligand activation of PPAR $\beta / \delta$ suppresses tumorigenicity in skin, colon and breast cancer models [15-17], but the mechanism mediating these effects remains unclear. Interestingly, four of four (100\%) human testicular embryonal carcinomas exhibit non-detectable to low expression of PPAR $\beta / \delta$ as compared to non-transformed tissue [18]. In the present study, a stable human testicular embryonal carcinoma cell lines over-expressing PPAR $\beta / \delta$ was established to investigate the mechanisms underlying the anti-tumorigenic effect of PPAR $\beta / \delta$ using in vitro and in vivo approaches.

\section{RESULTS}

\section{PPARß/ס inhibits proliferation, anchorage- independent cell growth, and MMP2 activity in testicular embryonal carcinoma cells}

NT2/D1-MigR1 (vector control) and NT2/D1$\mathrm{hPPAR} \beta / \delta$ cells expressed enhanced green fluorescent protein (eGFP), while control NT2/D1 cells were devoid of fluorescence (Figure 1A). Quantitative western blot or qPCR analysis further confirmed that NT2/D1-hPPAR $\beta / \delta$ cells over-expressed PPAR $\beta / \delta$ (Figure $1 \mathrm{~B}$ ), and exhibited enhanced expression of $A N G P T L 4 \mathrm{mRNA}$, a PPAR $\beta / \delta$ target gene, as compared to NT2/D1 parent cells or NT2/D1-MigR1 cells (Figure 1C). Ligand activation of PPAR $\beta / \delta$ with GW0742 robustly enhanced expression of ANGPTL4 mRNA in NT2/D1-hPPAR $\beta / \delta$ cells compared to controls (Figure 1C). While the higher concentrations
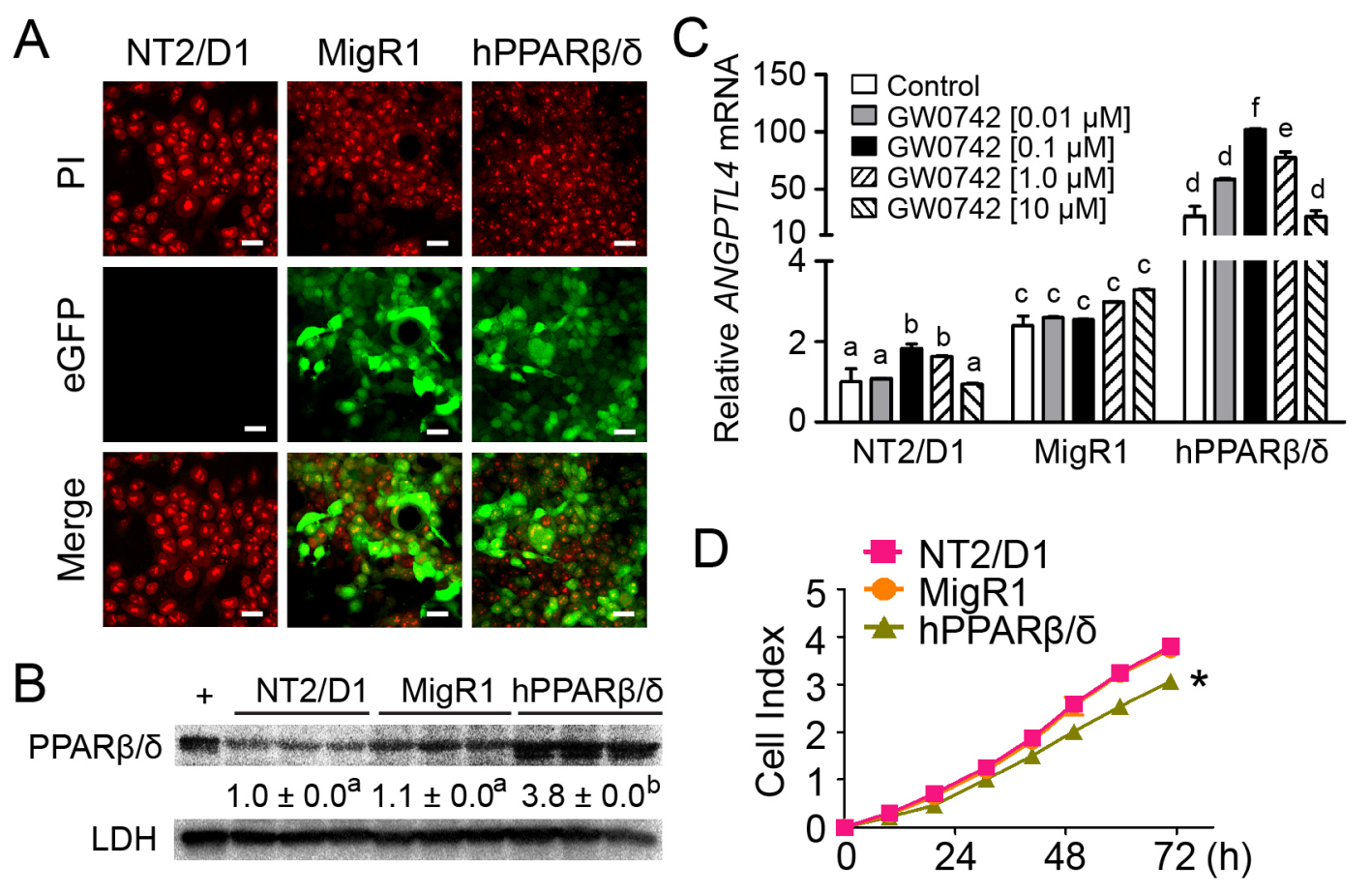

Figure 1: PPAR $\beta / \delta$ inhibits proliferation of human testicular embryonal carcinoma NT2/D1 cells. A. Representative
photomicrographs of NT2/D1, NT2/D1-MigR1 (MigR1, vector control) and NT2/D1-hPPAR $\beta / \delta$ (hPPAR $\beta / \delta$ ) cells showing positive eGFP
signals in MigR1 and hPPAR $\beta / \delta$ cells. PI staining indicates nuclei. Magnification $=600 \mathrm{X}$. Bar $=10 \mu$ m. B. Quantitative western blot
analysis of PPAR $\beta / \delta$ expression in NT2/D1, MigR 1 and hPPAR $\beta / \delta$ cells. + , positive control (cell lysate from COS 1 cells transfected with
human PPAR $\beta / \delta$ expression vector). Relative PPAR $\beta / \delta$ expression was normalized to LDH. C. Relative $A N G P T L 4$ mRNA expression as
compared to NT2/D1 cells with or without the PPAR $\beta / \delta$ agonist GW0742. D. Real-time proliferation of NT2/D1, MigR1 and hPPAR $\beta / \delta$
cells. Values represent mean \pm S.E.M. Values with different superscript letters are significantly different at $p \leq 0.05$. $*$ Significantly different
than control, $p \leq 0.05$. 
of GW0742 did not cause a dose dependent change in ANGPTL4 mRNA, this is likely due to limited quantity of receptor available for agonist activation, saturation of available receptors, and/or competition with endogenous agonists. NT2/D1-hPPAR $\beta / \delta$ cells exhibited a significant decrease in proliferation compared to controls (Figure 1D). However, no further inhibition of cell proliferation was observed following ligand activation of $\operatorname{PPAR} \beta / \delta$ in NT2/D1-hPPAR $\beta / \delta$ cells compared to controls (data not shown).

Another human embryonal carcinoma cell line, Tera2, was also examined. Similar to the results observed with NT2/D1 cells, Tera2 over-expressing PPAR $\beta / \delta$ (Tera2-hPPAR $\beta / \delta$ ) and its vector control (Tera2-MigR1) also expressed eGFP, while Tera2 cells showed no fluorescence (Figure 2A). Over-expression of PPAR $\beta / \delta$ in Tera 2 cells was confirmed by quantitative western blot analysis (Figure 2B). Higher constitutive expression of $A N G P T L 4$ mRNA in Tera2-hPPAR $\beta / \delta$ was observed compared to Tera 2 cells or Tera2-MigR1 cells (Figure 2C). Enhanced expression of ANGPTL4 mRNA was also observed following ligand activation of PPAR $\beta / \delta$ by GW0742 (Figure 2C). Over-expression of PPAR $\beta / \delta$ also significantly inhibited cell proliferation compared to controls (Figure 2D). However, no further inhibition of cell proliferation was observed following ligand activation of PPAR $\beta / \delta$ in Tera2-hPPAR $\beta / \delta$ cells compared to controls (data not shown).

Despite the observed inhibition of cell proliferation detected using real-time analysis of NT2/D1 cells over-expressing PPAR $\beta / \delta$, no difference in anchoragedependent clonogenicity was observed between NT2/ D1, NT2/D1-MigR1, or NT2/D1-hPPAR $\beta / \delta$ cells with or without over-expression and/or ligand activation of

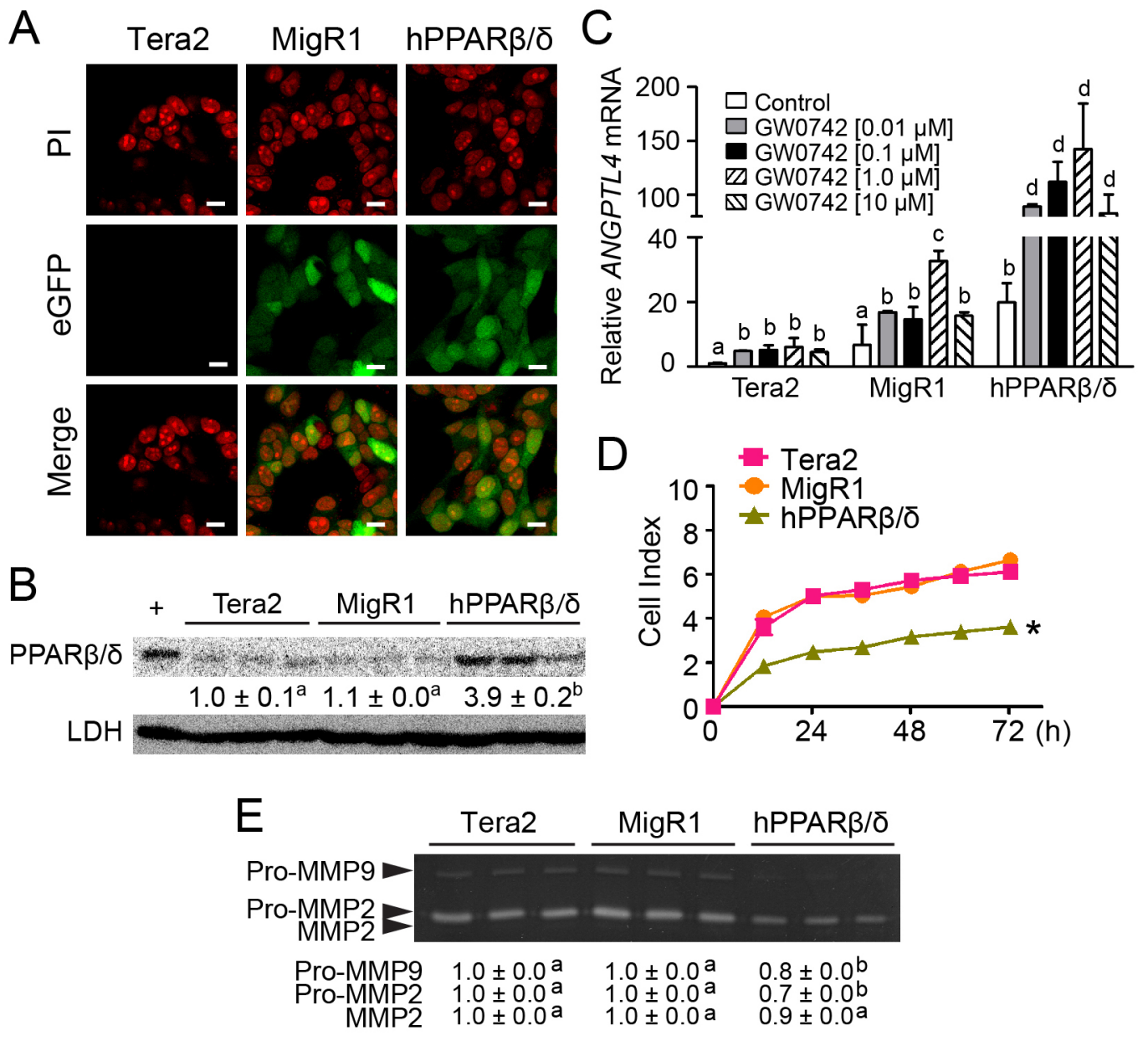

Figure 2: Characterization of human testicular embryonal carcinoma cell line Tera2 over-expressing PPAR $\beta / \delta$. A. Representative photomicrographs of Tera2, MigR 1 and hPPAR $\beta / \delta$ cells showing positive eGFP signals in MigR 1 and hPPAR $\beta / \delta$ cells. PI staining indicates cell nuclei. Magnification $=600 \mathrm{X}$. Bar $=10 \mu \mathrm{m}$. B. Quantitative western blot analysis of PPAR $\beta / \delta$ expression in Tera2, MigR1 and hPPAR $\beta / \delta$ cells. + , positive control (cell lysate from COS1 cells transfected with human PPAR $\beta / \delta$ expression vector). Relative PPAR $\beta / \delta$ expression was normalized to LDH. C. Cells were treated with the PPAR $\beta / \delta$ agonist GW0742 for 24 hours. ANGPTL4 mRNA expression was determined by qPCR and compared to the parent cell line. D. Real-time proliferation was examined in Tera2, MigR1 and hPPAR $\beta / \delta$ cells. E. Activities of MMP 2 and MMP9 in Tera2, MigR1 and hPPAR $\beta / \delta$ cells were determined by zymography. Values represent mean \pm S.E.M. Values with different superscript letters are significantly different at $p \leq 0.05$. *Significantly different than control, $p \leq 0.05$. 
PPAR $\beta / \delta$ (Figure 3A). The reason why over-expression of PPAR $\beta / \delta$ caused inhibition of cell proliferation as observed using real-time analysis but had no effect on clonogenicity cannot be determined from these experiments. By contrast, anchorage-independent cell growth was decreased in NT2/D1-hPPAR $\beta / \delta$ cells compared to controls (Figure 3B-3D). MMP activity promotes anchorage-independent transformation [19], and NT2/D1 and Tera2 cells predominately expressed MMP2 (Figure 2E, 3E). Thus, it is of interest to note that MMP2 activity was decreased by $50 \%$ and $30 \%$ in NT2/ D1-hPPAR $\beta / \delta$ and Tera2-hPPAR $\beta / \delta$ cells compared to their controls, respectively (Figure 2E, 3E).

\section{$\mathrm{PPAR} \beta / \delta$ suppresses tumor growth and is associated with reduced cell proliferation and increased necrosis and differentiation}

Average tumor volume and weight of ectopic xenografts developing from NT2/D1-hPPAR $\beta / \delta$ cells were markedly smaller compared to controls (Figure $4 \mathrm{~A}-4 \mathrm{D})$. It is worth noting that the tumor incidence was reduced by $40 \%$ in mice injected with NT2/D1-hPPAR $\beta / \delta$ cells $(6 / 10)$ compared to controls $(10 / 10)$. The incidence of tumor formation was decreased further by ligand activation of PPAR $\beta / \delta(4 / 10)$ in mice injected with NT2/ D1-hPPAR $\beta / \delta$ cells and $(6 / 10)$ in mice injected with NT2/

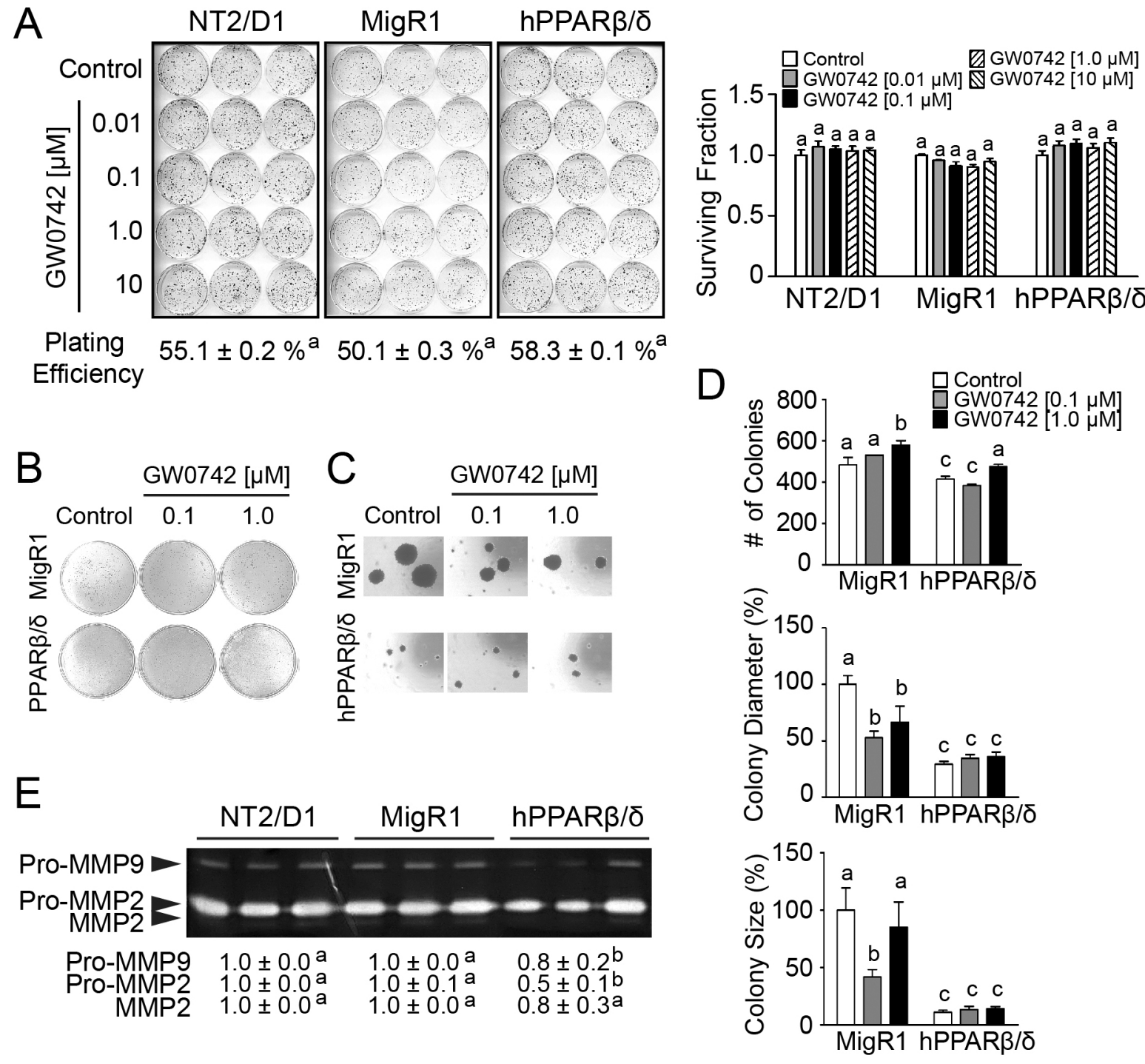

Figure 3: PPAR $\beta / \delta$ inhibits MMP activities and anchorage-independent clonogenicity of human testicular embryonal carcinoma NT2/D1 cells. A. Left panel, anchorage-dependent clonogenicity of NT2/D1, MigR1 or hPPAR $\beta / \delta$ cells treated with or without GW0742. Right panel, plating efficiency and survival fraction of anchorage-dependent clonogenicity assay. B. Anchorageindependent clonogenicity of MigR 1 and $\mathrm{hPPAR} \beta / \delta$ cells with or without GW0742. C. Representative photomicrographs of colonies on soft agar $($ Magnification $=200 X)$. D. Quantification of colonies, diameter of the colonies, and the size of the colonies on soft agar. E. Activities of MMP2 and MMP9 in NT2/D1, MigR1 and hPPAR $\beta / \delta$ cells. Values represent the mean \pm S.E.M. Values with different superscript letters are significantly different at $p \leq 0.05$. * Significantly different than control, $p \leq 0.05$. 

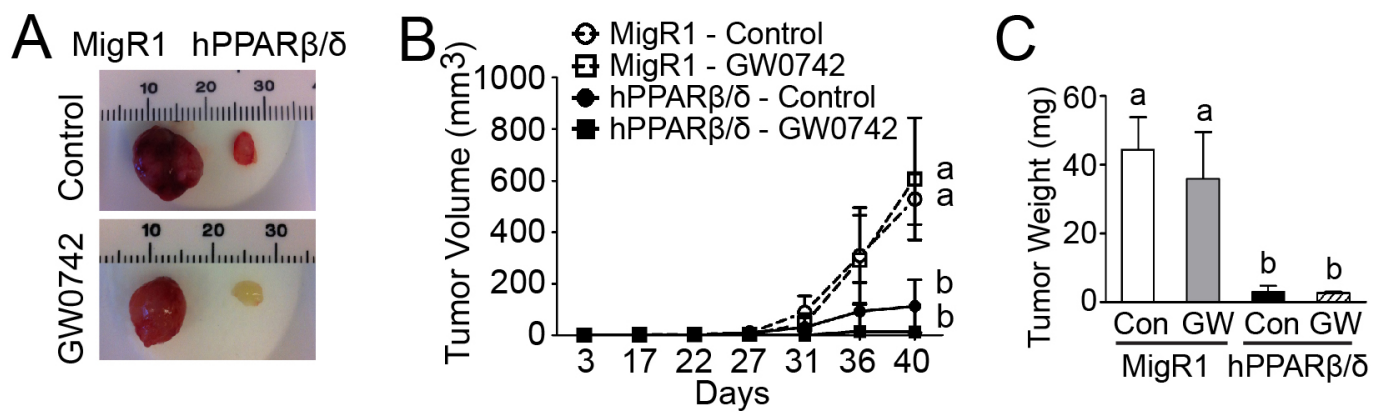

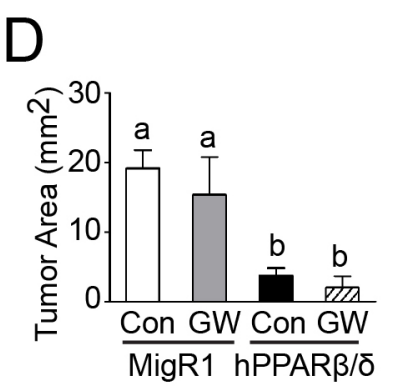

E
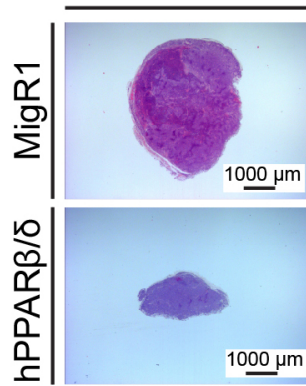

Control
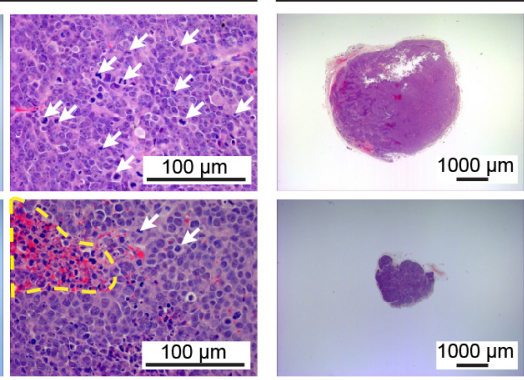

GW0742

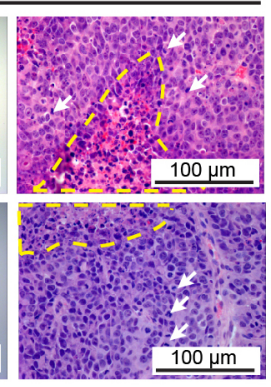

$\mathrm{F}$

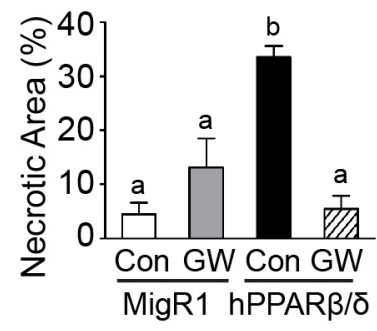

G
Control

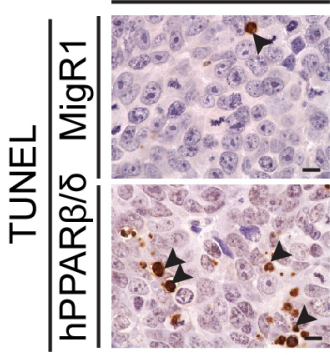

GW0742

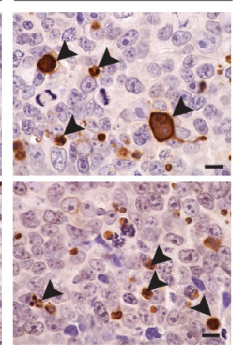

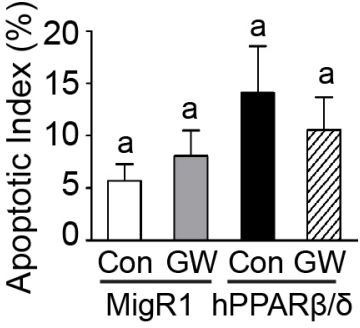

Figure 4: PPAR $\beta / \delta$ attenuates tumor growth in testicular cancer xenografts by inducing necrosis. A. Representative photomicrographs of xenografts derived from NT2/D1-MigR1 (MigR1) and NT2/D1-hPPAR $\beta / \delta$ (hPPAR $\beta / \delta$ ) cells. B. Average tumor volumes over time. C. Average tumor weight at the end of the study. D. Average tumor area in paraffin-embedded tumor sections. E. Representative photomicrographs of H\&E-stained xenografts. The nuclei of tumor cells were large, pleomorphic and round to spindle, and mitotic figures (white arrows) were frequently observed. Necrotic areas are marked with a yellow dashed line. Magnification $=12.5 \mathrm{X}$ (left) and 400X (right). F. Average percentage of necrotic area normalized by total tumor area in tumor sections. G. Apoptosis in xenograft tumors was determined by TUNEL assay. Left panel, apoptotic tumor cells were indicated by arrowheads. Magnification $=1000 \mathrm{X}$. Bar $=$ $10 \mu \mathrm{m}$. Right panel, quantification of apoptotic index in tumor sections. Control $=(\mathrm{Con})$; GW0742-treated $(2.5 \mathrm{mg} / \mathrm{kg} / \mathrm{day})=(\mathrm{GW})$. Values represent the mean \pm S.E.M. Values with different superscript letters are significantly different at $p \leq 0.05$.

D1-MigR1 cells. Histopathological analysis indicated that tumor cells of control xenografts were immature and highly mitotic, indicative of malignancy (Figure $4 \mathrm{E})$. In contrast, over-expression and/or ligand activation of PPAR $\beta / \delta$ decreased the size of xenografts compared to controls (Figure 4D and 4E). However, no changes in mitotic indices were noted between groups (date not shown). Interestingly, over-expression of PPAR $\beta / \delta$ caused an increase in necrosis in xenografts from mice injected with NT2/D1-hPPAR $\beta / \delta$ cells, and this effect was not observed in any other group (Figure 4F). A modest increase in apoptosis was observed in xenografts developing from NT2/D1-hPPAR $\beta / \delta$ cells but this effect was not statistically significant (Figure 4G). Further, induced apoptosis in the cell lines was examined in greater detail following treatment with either staurosporine or ultraviolet B (UVB) light exposure. However, no significant changes in poly adenosine diphosphate-ribose polymerase (PARP)cleavage were observed following staurosporine treatment or UVB exposure among NT2/D1, NT2/D1-MigR1 and 
NT2/D1-hPPAR $\beta / \delta$ cells (data not shown). Expression of PPAR $\beta / \delta$ was notably higher in xenografts from mice injected with NT2/D1-hPPAR $\beta / \delta$ cells as compared to controls (Figure $5 \mathrm{~A}$ ), and ligand activation of PPAR $\beta / \delta$ caused a marked increase in expression of ANGPTL4 in xenografts from mice injected with NT2/D1-hPPAR $\beta / \delta$ cells as compared to controls (Figure 5B). Expression of PCNA (a biomarker of proliferation) and OCT3/4 (a biomarker of invasion, migration, and differentiation) was decreased by ligand activation of $\operatorname{PPAR} \beta / \delta$ in
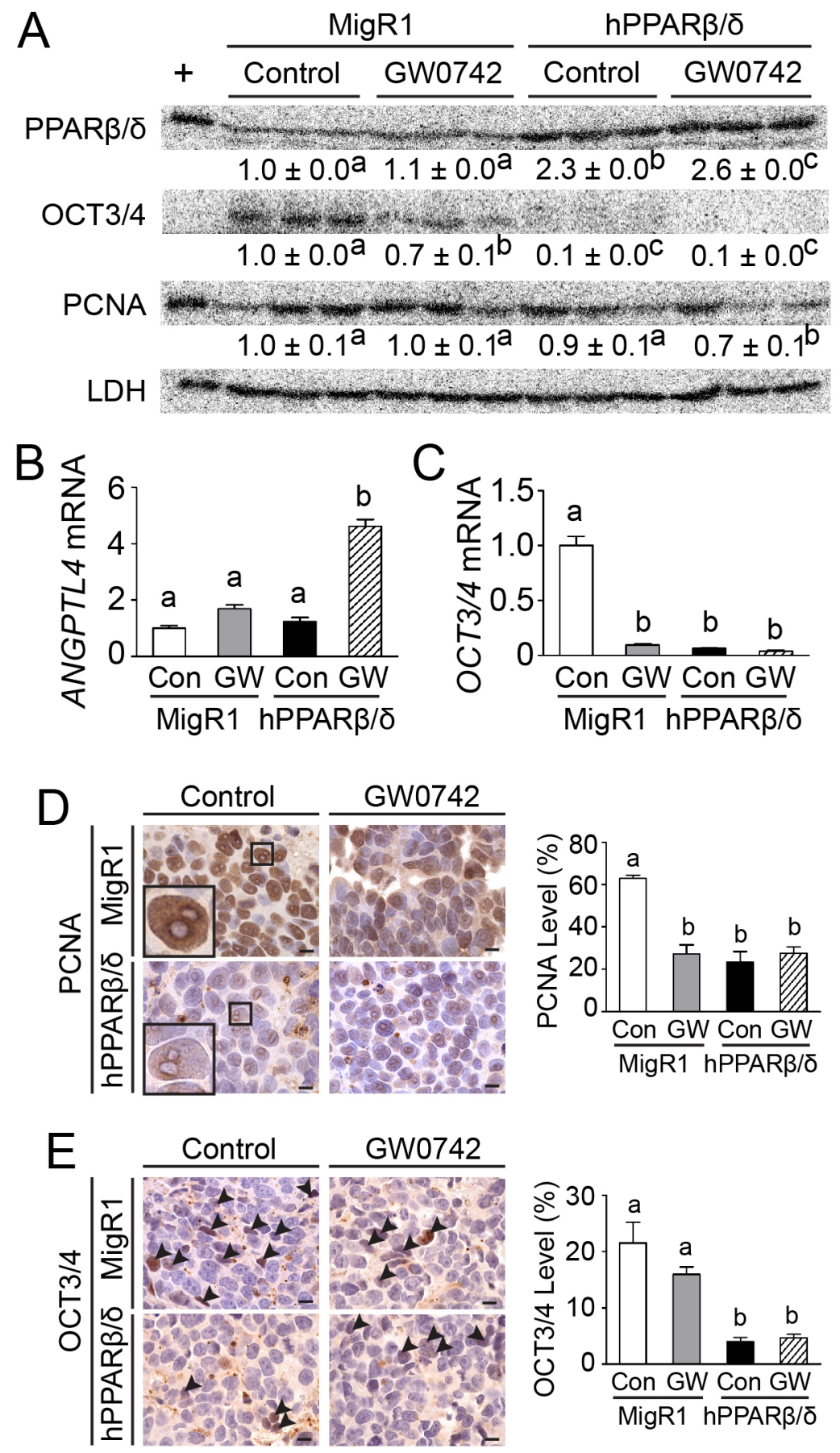

Figure 5: PPAR $\beta / \delta$ induces differentiation and inhibits proliferation in testicular cancer xenografts. A. the expression of $\mathrm{PPAR} \beta / \delta$, OCT $3 / 4$ and PCNA of tumors were determined by quantitative western blot analysis. + , positive control (cell lysate from COS1 cells transfected with human PPAR $\beta / \delta$ expression vector). Relative expression of target protein was normalized to LDH. B. ANGPTL4 and C. OCT3/4 mRNA expression in xenografts. D, E. Left panel, representative photomicrographs of xenografts showing the expression of PCNA and OCT3/4 (arrowheads), respectively, assessed by immunohistochemistry. Magnification $=1000 \mathrm{X}$. Bar $=10 \mu \mathrm{m}$. D, E. Right panel, quantification of PCNA and OCT3/4 in xenografts. Control $=(\mathrm{Con}) ; \mathrm{GW} 0742$-treated $(2.5 \mathrm{mg} / \mathrm{kg} / \mathrm{day})=(\mathrm{GW})$. Values represent the mean \pm S.E.M. Values with different superscript letters are significantly different at $p \leq 0.05$. 
xenografts from mice injected with NT2/D1-MigR1 cells as compared to controls (Figure 5A and 5C-5E). Moreover, the expression of PCNA and OCT3/4 was decreased by expression and/or ligand activation of $\operatorname{PPAR} \beta / \delta$ in xenografts from mice injected with NT2/D1-hPPAR $\beta / \delta$ cells as compared to controls (Figure $5 \mathrm{~A}$ and $5 \mathrm{C}-5 \mathrm{E}$ ).

\section{PPAR $\beta / \delta$-dependent attenuation of MMP2- mediated invasion and migration of NT2/D1 cells}

A real-time invasion assay using human umbilical cord vascular endothelial cells (HUVEC) showed that
NT2/D1-hPPAR $\beta / \delta$ cells exhibited weaker invasion through the HUVEC monolayer compared to NT2/D1MigR1 and NT2/D1 cells, but that ligand activation of $\mathrm{PPAR} \beta / \delta$ did not further enhance this effect (Figure 6). In two other transwell assays, over-expression and/or ligand activation of PPAR $\beta / \delta$ in NT2/D1 cells suppressed invasion and migration compared to controls (Figure 7A and $7 \mathrm{~B})$. In NT2/D1-hPPAR $\beta / \delta$ cells, invasion and migration as assessed using the real-time $\mathrm{xCELLigence}$ system, was reduced as compared to NT2/D1-MigR1 and NT2/D1 cells (Figure 7C and 7D). Inhibition of invasion using the real-time xCELLigence system was also
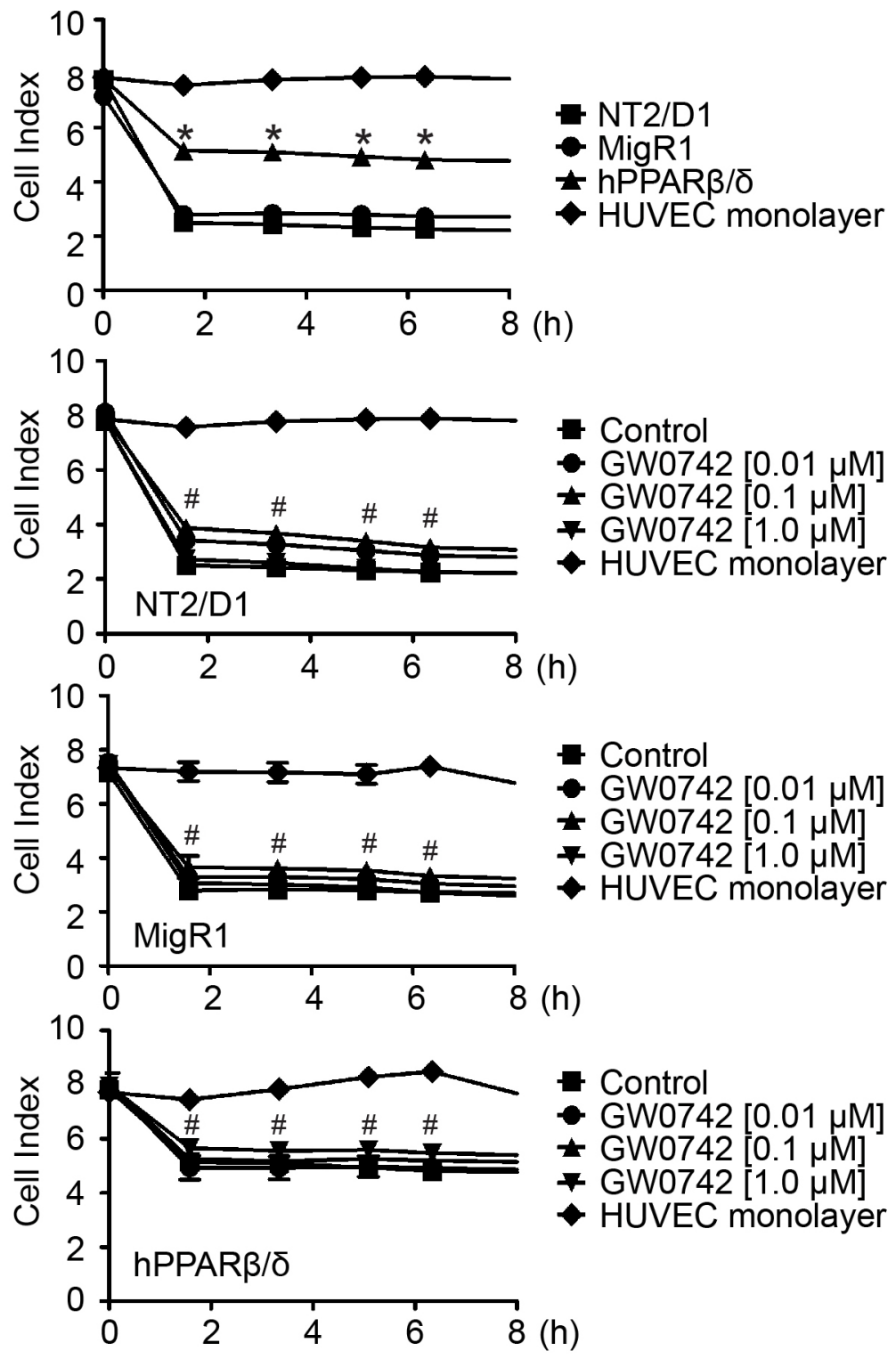

Figure 6: Over-expression of PPARß/ס decreases testicular cancer cell invasion of a HUVEC monolayer. Testicular cancer cell-endothelial cell interaction was detected in real-time using an xCELLigence system. NT2/D1 cell lines were seeded on top of HUVEC monolayer, and cell index was recorded up to 8 hours. Over-expression of PPAR $\beta / \delta$ increased the cell index, indicating a suppression of cell invasion through the HUVEC monolayer. No changes in cell index were observed among NT2/D1 cell lines following GW0742 treatment. Values represent mean \pm S.E.M. *Significantly different than NT2/D1 cell control, $p \leq 0.05$. \#Significantly different than the HUVEC negative control, $p \leq 0.05$. 


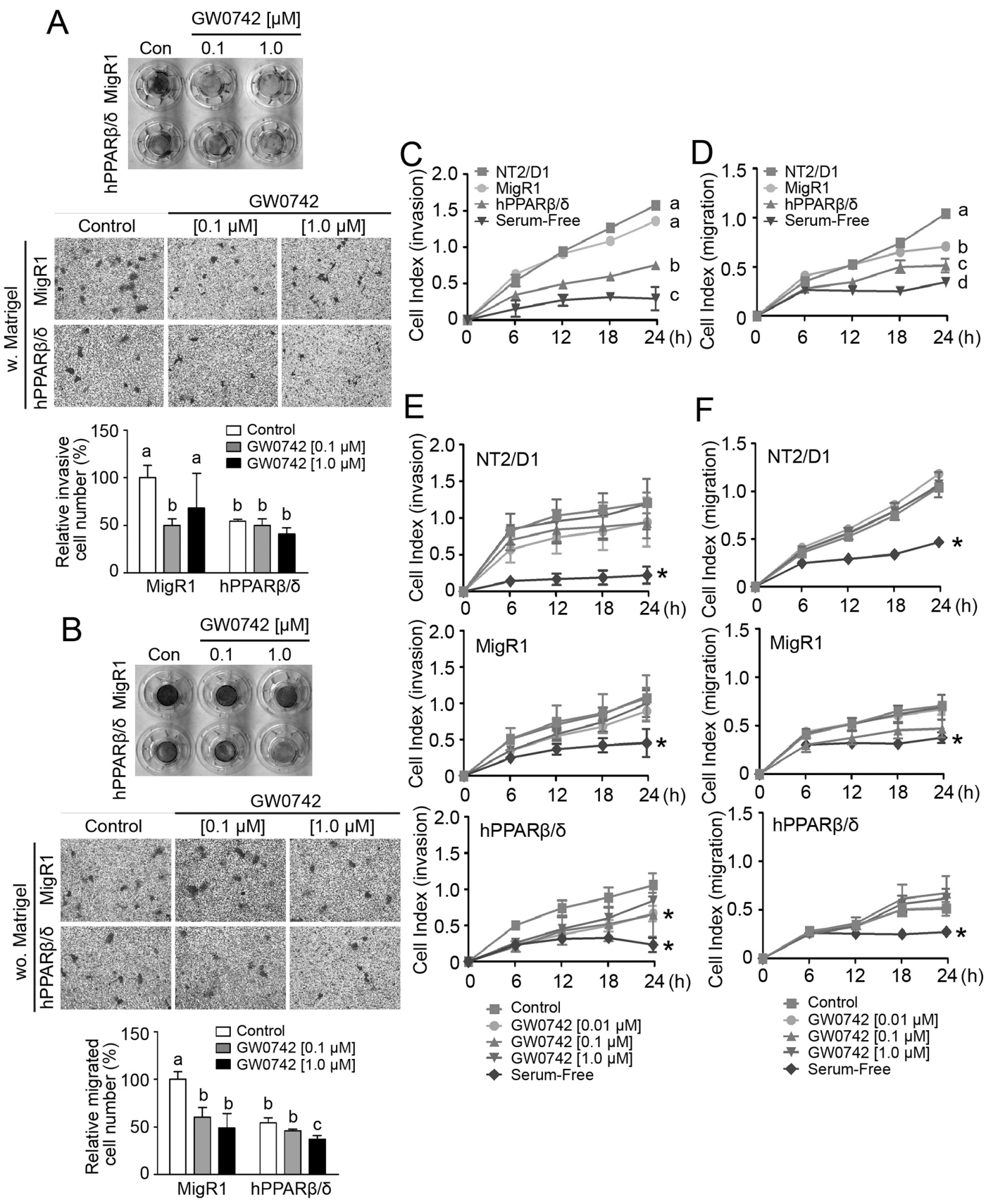

Figure 7: PPARß/ס inhibits invasion and migration of NT2/D1 cells. A. Upper panel, representative photographs of transwell inserts in invasion assay. A. Middle panel, representative photomicrographs of invasive cells on the lower surface of the transwell inserts. Magnification $=200 X$. A. Lower panel, quantification of invasive cells normalized to NT2/D1-MigR1 (MigR1) control group. B. Upper panel, representative photographs of transwell inserts in migration assay. B. Middle panel, representative photomicrographs of migrated cells on the lower surface of the transwell inserts. Magnification $=200 X$. B. Lower panel, quantification of migrated cells normalized to MigR1 control group. w: with matrigel; wo: without matrigel. C, D. Real-time invasion or migration, respectively, in NT2/D1, MigR1 and NT2/D1-hPPAR $\beta / \delta(h P P A R \beta / \delta$ ) cells. E, F. Real-time invasion and migration, respectively, of NT2/D1, MigR1 and hPPAR $\beta / \delta$ cells with or without GW0742. Serum-free cells were the negative control. Values represent the mean \pm S.E.M. Values with different superscript letters are significantly different at $p \leq 0.05$. *Significantly different than control, $p \leq 0.05$. 
observed in NT2/D1-hPPAR $\beta / \delta$ cells following ligand activation of PPAR $\beta / \delta$ (Figure 7E), but ligand activation of PPAR $\beta / \delta$ had no further influence on migration in any of the cell lines tested (Figure 7F).

To determine whether the effects of over-expression and/or ligand activation on invasion and migration required PPAR $\beta / \delta$, cells were co-treated with and without a PPAR $\beta / \delta$ agonist (GW0742) and/or an antagonist (GSK3787). MMP2 zymographic activity was lower in response to ligand activation of PPAR $\beta / \delta$ with GW0742, and higher in response to the PPAR $\beta / \delta$ antagonist GSK3787 in NT2/D1-MigR1 cells compared to controls (Figure 8A). Co-treatment with GSK3787 and GW0742 mitigated the reduction in MMP2 activity in NT2/D1MigR 1 cells caused by ligand activation of PPAR $\beta / \delta$ alone, compared to controls (Figure 8A). MMP2 zymographic activity in NT2/D1-hPPAR $\beta / \delta$ cells was markedly lower, but ligand activation, treatment with the antagonist or cotreatment with the agonist and antagonist had no further effect on this reduced MMP2 zymographic activity compared to controls (Figure 8A). To demonstrate that MMP2 is required for the PPAR $\beta / \delta$-dependent changes in invasion and migration, a specific MMP2 inhibitor was examined in these models. Indeed, over-expression of $\mathrm{PPAR} \beta / \delta$ in NT2/D1-hPPAR $\beta / \delta$ cells caused a decrease in cell invasion and migration, as assessed by real-time analyses using the xCELLigence system, and it was comparable to that observed with the MMP2 inhibitor SB3CT (Figure 8B and 8C). Similar results were observed the standard transwell model (data not shown). Further, a wound healing assay showed decreased migration in NT2/D1-hPPAR $\beta / \delta$ cells by treatment with SB-3CT as compared to controls (Figure 8D).

\section{PPAR// $\delta$ decreases MMP2 activity by competing with RXR and interfering with RAR signaling in NT2/D1 cells}

The mechanism by which $\mathrm{PPAR} \beta / \delta$ regulates MMP2 expression was examined next. The relative availability of different factors including intracellular RXR can influence the activities of PPARs and RARs $[10,12]$. A putative RAR RE was identified in the human $M M P 2$ promoter (Figure 9A). Interestingly, some studies show that atRA can inhibit MMP2 activity [20,21], while others indicate that atRA can increase MMP2 activity $[22,23]$. Thus, the hypothesis that competition between PPAR $\beta / \delta$ and RAR for the availability of RXR required to activate RAR and modulate MMP2 activity was examined. EMSA was performed and two DNA-protein complexes were detected for the putative RAR RE in the $M M P 2$ promoter (Figure 9B). The binding activities were weaker in the nuclear extracts from NT2/D1-hPPAR $\beta / \delta$ cells compared to that from NT2/D1-MigR1 cells (Figure 9B), suggesting that over-expression of PPAR $\beta / \delta$ competed for RXR binding and reduced the formation of RAR/ RXR heterodimers and binding with the $M M P 2$ promoter. The binding activities were diminished using mutant oligonucleotides, and a super-shift complex was observed in the presence of an anti-RAR $\alpha$ antibody for the RAR RE (Figure 9B). Importantly, ChIP assays revealed reduced promoter occupancy of RAR on the $M M P 2$ promoter in NT2/D1-hPPAR $\beta / \delta$ cells than that in NT2/D1-MigR1 cells (Figure 9C). To more definitively examine the competition between RAR and PPAR $\beta / \delta$ for RXR, NT2/D1 cells were transiently transfected with an RAR $\alpha$ expression vector (Figure 9D). The RAR $\alpha$ target gene CYP26A1 and MMP2 mRNA expression were increased in atRA-treated NT2/ D1-MigR1 cells compared to controls, and this induction was greater by over-expressing RAR $\alpha$ (Figure 9E and 9F). In contrast, atRA had limited effect on the expression of $C Y P 26 A 1$ and $M M P 2 \mathrm{mRNA}$ in NT2/D1-hPPAR $\beta / \delta$ cells compared to similarly treated NT2/D1-MigR1 cells with over-expression of RAR $\alpha$ (Figure 9E and 9F). atRA induced MMP2 activity in NT2/D1-MigR1 cells, and this effect was greater in NT2/D1-MigR1 cells over-expressing RAR $\alpha$ compared to controls (Figure 9G). No significant changes in MMP2 activity were detected in NT2/D1$\mathrm{hPPAR} \beta / \delta$ cells over-expressing RAR $\alpha$ with or without atRA treatment (Figure 9G). Moreover, ChIP-qPCR demonstrated increased occupancy of RAR $\alpha$ on the RAR $\mathrm{RE}$ of the $M M P 2$ promoter following atRA treatment in NT2/D1, and NT2/D1-MigR1 cells, and this induction was attenuated by ligand activation of PPAR $\beta / \delta$ (Figure $9 \mathrm{H}$ ). Over-expression of PPAR $\beta / \delta$ decreased the occupancy of RAR $\alpha$ on $M M P 2$ promoter in NT2/D1-hPPAR $\beta / \delta$ cells, and the effect of atRA treatment or transient overexpression of RAR $\alpha$ on occupancy of RAR $\alpha$ on the MMP2 promoter in NT2/D1-hPPAR $\beta / \delta$ cells was negligible (Figure 9H).

A previous study suggested that atRA can mediate pro-tumorigenic effects in cells exhibiting a relatively high FABP5:CRABPII ratio because the FABP5 putatively "delivered" agonists to PPAR $\beta / \delta$ [24]. Since NT2/D1hPPAR $\beta / \delta$ cells exhibit a relatively high FABP5:CRABPII ratio compared to control NT2/D1 cells (Figure 10), the effect of atRA on invasion and migration was examined to determine if this mechanism modulated the observed phenotype of the model in the present study (Figure 11). These analyses indicated that atRA signaling mediated by RAR/RXR is not dependent on PPAR $\beta / \delta$ in NT2/D1 cells that exhibit a relatively high FABP5:CRABPII ratio (Figure 10).

\section{DISCUSSION}

Testicular embryonal carcinoma is highly aggressive and metastatic [5]. Interestingly, increasing expression of PPAR $\beta / \delta$ in testicular embryonal carcinoma NT2/D1 cells inhibits anchorage independent transformation, consistent 

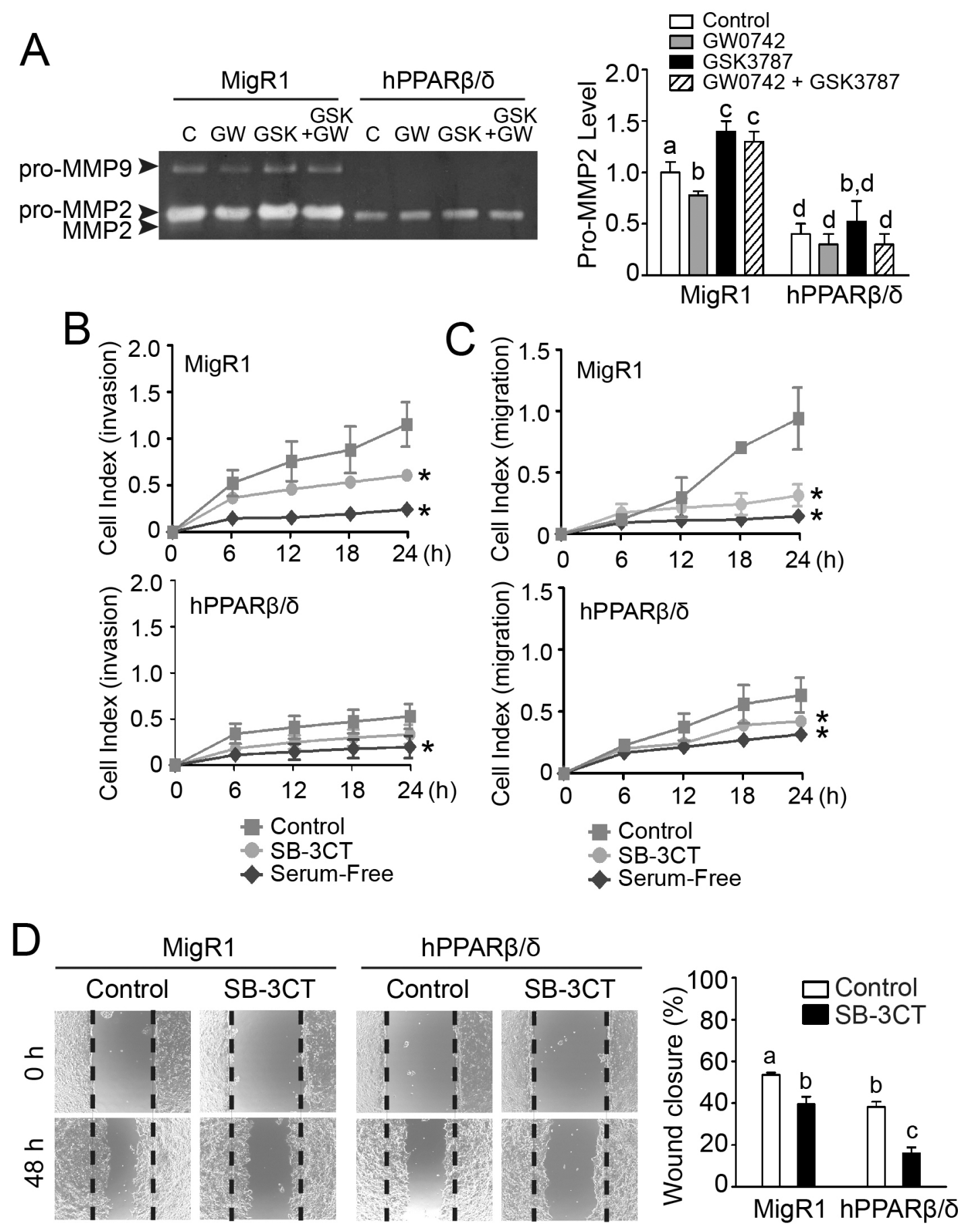

Figure 8: PPARß/ס-dependent attenuation of MMP2-mediated invasion and migration of NT2/D1 cells. A. Left panel, activities of MMP2 and MMP9 in NT2/D1-MigR1 (MigR1) and NT2/D1-hPPAR $\beta / \delta$ (hPPAR $\beta / \delta$ ) cells treated with vehicle control (C) GW0742 (GW), and/or GSK3787 (GSK). Right panel, relative activity of pro-MMP2. B, C. Real-time invasion or migration of MigR1 and hPPAR $\beta / \delta$ cells in response to SB-3CT. D. Left panel, representative photomicrographs of wound-healing migration assay in MigR1 and $\mathrm{hPPAR} \beta / \delta$ cells in response to SB-3CT treatment and, right panel, the average percentage of wound closure after $48 \mathrm{~h}$. Values represent the mean \pm S.E.M. Values with different superscript letters are significantly different at $p \leq 0.05$. *Significantly different than control, $p \leq 0.05$.

with the observed inhibition of xenograft development from NT2/D1 cells. Results from these studies elucidated two unique mechanisms by which PPAR $\beta / \delta$ inhibits tumorigenesis.
Initiation of testicular cancer is associated with altered differentiation of spermatogonia as they develop stem cell-like properties [25]. The mechanism(s) that mediate this reprogramming is/are not fully understood. 
A

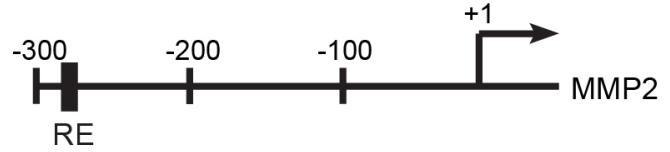

B Oligo ++++---+++++Mutant Oligo ----++++-----anti-RARa Ab -------++++-MigR1-NE ++--++--++---+ hPPARß/ס-NE --++--++--++-+

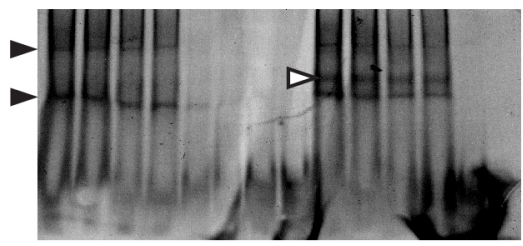

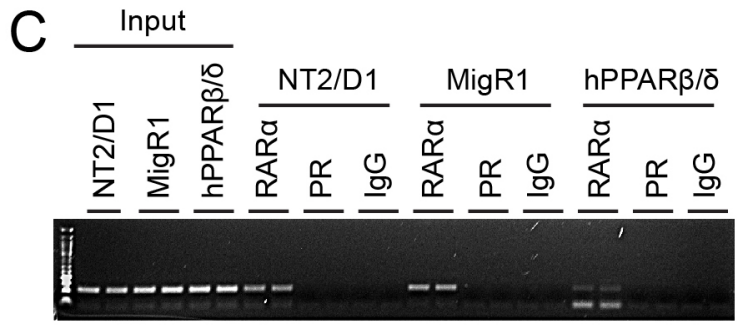

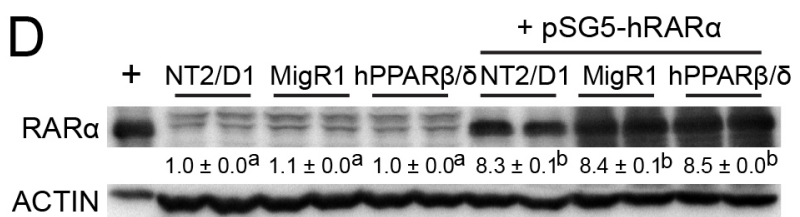

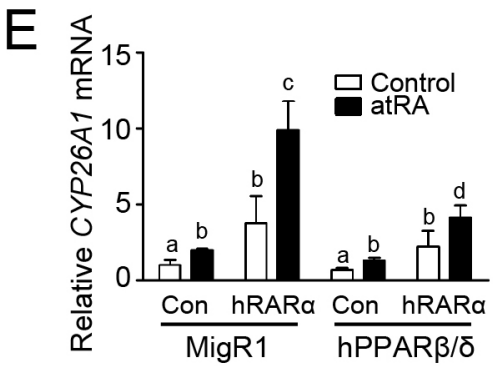

$\mathrm{F}$

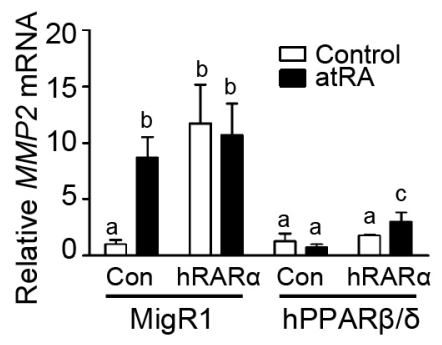

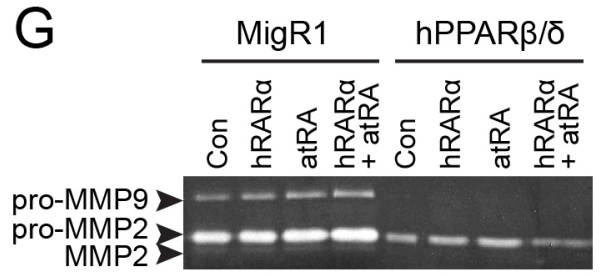

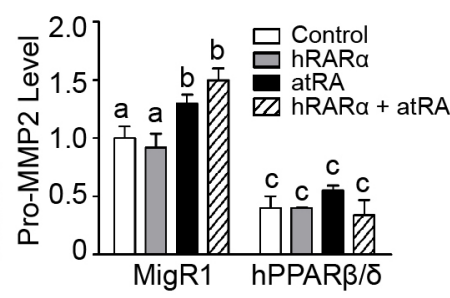

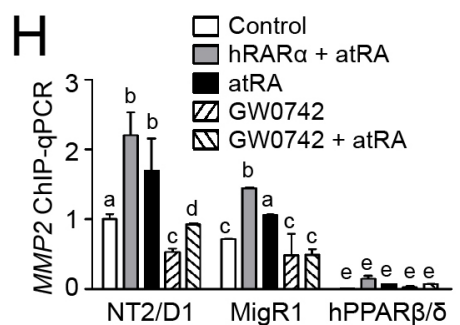

Figure 9: PPARß/ס suppresses MMP2 activity by interfering with RAR signaling. A. A putative RAR RE in the human $M M P 2$ promoter. +1 represented the transcriptional start site. B. Representative EMSA of nuclear extracts from NT2/D1-MigR1 (MigR1) and NT2/D1-hPPAR $\beta / \delta(h P P A R \beta / \delta$ ) cells were incubated with either double-stranded oligonucleotides (oligo) encoding the RAR RE $M M P 2$ promoter or mutated oligonucleotides (mutant oligo). Black arrowheads indicated the presence of oligonucleotide-protein complexes. White arrowheads indicated the super shift of oligonucleotide-protein-anti-RAR-antibody complexes. C. Representative photomicrograph of the ChIP assay for RAR occupancy on the $M M P 2$ promoter. D. RAR $\alpha$ protein expression in NT2/D1, MigR 1 and hPPAR $\beta / \delta$ cells transiently transfected with pSG5-RAR $\alpha$ plasmid. E, F. CYP26A1 and MMP2 mRNA expression in MigR1 and hPPAR $\beta / \delta$ cells or cells transiently over-expressing RAR $\alpha$ after atRA treatment, respectively. G. Left panel, activities of MMP2 and MMP9 in MigR1 and hPPAR $\beta / \delta$ cells transiently over-expressing RAR after atRA treatment, right panel, relative activity of pro-MMP2 in MigR1 and hPPAR $\beta / \delta$ cells. H. ChIPqPCR showing effect of PPAR $\beta / \delta$ on RAR $\alpha$ occupancy on $M M P 2$ promoter in cells over-expressing PPAR $\beta / \delta$ or RAR $\alpha$ following atRA and/or GW0742 treatment. Values represent mean \pm S.E.M. Values with different superscript letters are significantly different at $p \leq 0.05$.

Increased expression of OCT3/4 is associated with dedifferentiation and induction of pluripotency [26]. Overexpression of $\mathrm{PPAR} \beta / \delta$ causes decreased expression of OCT3/4 in xenograft tumors and NT2/D1 cells, suggesting that PPAR $\beta / \delta$ promotes differentiation in these testicular cancer models. Since the induction of terminal differentiation is known to be associated with withdrawal from the cell cycle [27], it is of interest to note that overexpression of PPAR $\beta / \delta$ decreased cell proliferation of
NT2/D1 cells and notably in xenografts as revealed by decreased PCNA. Thus, the inhibitory effect of PPAR $\beta / \delta$ on tumorigenicity may be partially linked with PPAR $\beta / \delta$ induced differentiation modulated by PPAR $\beta / \delta$-dependent decrease in OCT3/4. However, there remains a need to distinguish whether PPAR $\beta / \delta$ directly triggers cancer cell differentiation and suppresses tumorigenesis, or if it involves developmental reprogramming and causes the reversal of tumorigenesis by decreasing the pluripotency 
A

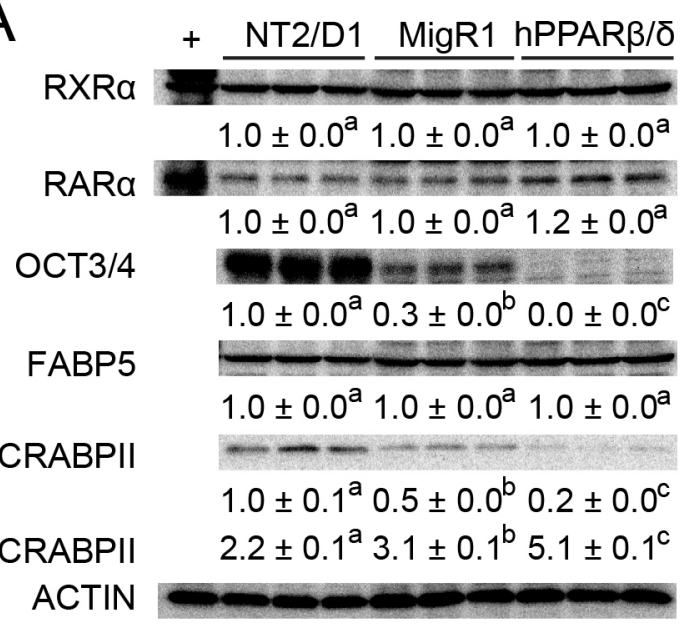

B

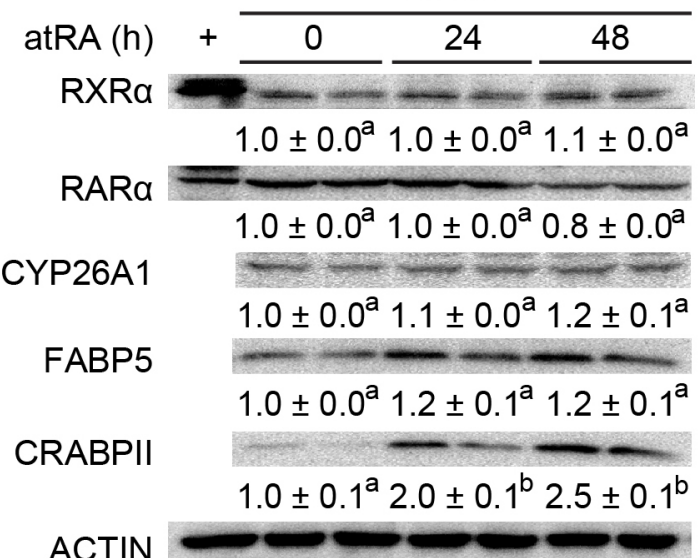

\begin{tabular}{|c|c|c|c|c|c|}
\hline \multirow[b]{2}{*}{ atRA $(\mathrm{h})$} & \multicolumn{2}{|l|}{ MigR1 } & \multicolumn{3}{|c|}{ hPPAR $\beta / \delta$} \\
\hline & 24 & 48 & 0 & 24 & 48 \\
\hline \multirow[t]{2}{*}{ RXRa I } & $1=0+1=-1$ & $-\infty$ & $-m$ & $2=$ & $=-5$ \\
\hline & $1.0 \pm 0.1^{a} 0.8 \pm 0.0^{a}$ & $0.8 \pm 0.1^{a}$ & $0.7 \pm 0.1^{a}$ & $0.8 \pm 0.0^{a}$ & $0.7 \pm 0.1^{a}$ \\
\hline \multirow{2}{*}{ RAR $\alpha$} & $-1-\square$ & -1 & -1 & 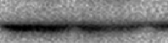 & 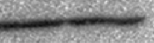 \\
\hline & $1.0 \pm 0.1^{a} 0.8 \pm 0.1^{a}$ & $0.8 \pm 0.0^{a}$ & $0.7 \pm 0.0^{a}$ & $0.8 \pm 0.0^{\mathrm{a}}$ & $0.7 \pm 0.0^{a}$ \\
\hline \multirow[t]{2}{*}{ CYP26A1 } & 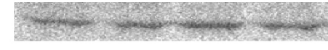 & nes & 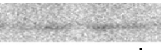 & 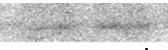 & 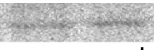 \\
\hline & $1.0 \pm 0.1^{a} 1.1 \pm 0.1^{a}$ & $1.2 \pm 0.0^{a}$ & $0.5 \pm 0.0^{b}$ & $0.6 \pm 0.1^{b}$ & $0.6 \pm 0.1^{b}$ \\
\hline \multirow[t]{2}{*}{ FABP5 } & $--1-1$ & $-\div-=$ & --- & $=-$ & -1 \\
\hline & $1.0 \pm 0.1^{a} 0.7 \pm 0.1^{a}$ & $0.7 \pm 0.0^{a}$ & $0.7 \pm 0.0^{a}$ & $0.8 \pm 0.1^{\mathrm{a}}$ & $0.7 \pm 0.1^{\mathrm{a}}$ \\
\hline \multirow[t]{2}{*}{ CRABPII } & 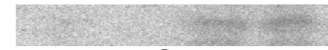 & 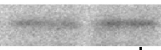 & 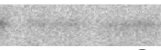 & 25 & 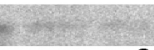 \\
\hline & $1.0 \pm 0.2^{a} 1.2 \pm 0.0^{a}$ & $1.8 \pm 0.1^{b}$ & $0.9 \pm 0.0^{a}$ & $1.7 \pm 0.0^{b}$ & $0.8 \pm 0.0^{a}$ \\
\hline
\end{tabular}

Figure 10: PPARß/ $\delta$ interferes with atRA-stimulated signaling in NT2/D1 cells. A. Quantitative western blot analysis of RXR $\alpha$, RAR $\alpha$, OCT3/4, FABP5 and CRABPII expression in NT2/D1, NT2/D1-MigR1 (MigR1) and NT2/D1-hPPAR $\beta / \delta$ (hPPAR $\beta / \delta$ ) cells. B, C. Quantitative western blot analysis of RXR $\alpha$, RAR $\alpha$, CYP26A1, FABP5 and CRABPII expression in NT2/D1, MigR1 and hPPAR $\beta / \delta$ cells in response to atRA treatment. Values represent mean \pm S.E.M. Values with different superscript letters are significantly different at $p \leq 0.05$.

of cancer stem cells. Why expression of PPAR $\beta / \delta$ inhibited proliferation of NT2/D1 cells in vitro but ligand activation of PPAR $\beta / \delta$ with a synthetic agonist did not, cannot be determined from these studies. However, the lack of a tumor microenvironment and/or competition with endogenous ligands that may exhibit greater affinity for the receptor could explain this difference.

While relative over-expression of PPAR $\beta / \delta$ is comparable between Tera2 and NT2/D1 cells, the effect on cell proliferation by its over-expression is more robust in Tera2 than in N2/D1 cells. NT2/D1 cells are derived from a single-cell clone of NTERA2 cells originated from xenograft tumors from Tera2 cells in nude mice [28]. Tera-2 cells are highly heterogeneous and consist of only $2-3 \%$ of embryonal carcinoma stem cells [29]. Compared to Tera2 cells, NT2/D1 cells represent robust pluripotent embryonal stem cell properties, and are more susceptible to retinoic acid-induced neural differentiation by developing neuronal morphology and exhibiting diminished expression of stem cell makers [29-31]. These differences could contribute to the differential response of NT2/D1 and Tera2 cells on cell proliferation following over-expression of PPAR $\beta / \delta$. Additionally, NT2/D1 cells also exhibit a similar pattern of DNA methylation as testicular cancer patients at later stage of malignancy [32], suggesting that NT2/D1 cells are more metastatic than Tera 2 cells. Thus, these unique characters of NT2/D1 cells allow for examining the role of PPAR $\beta / \delta$ in cancer stem cells and tumor progression.

MMPs promote cancer cell migration, invasion and metastasis. Some studies show that ligand activation of PPAR $\beta / \delta$ increases MMP-dependent cell migration, invasion and metastasis $[33,34]$, whereas other studies demonstrate that ligand activation of PPAR $\beta / \delta$ inhibits 

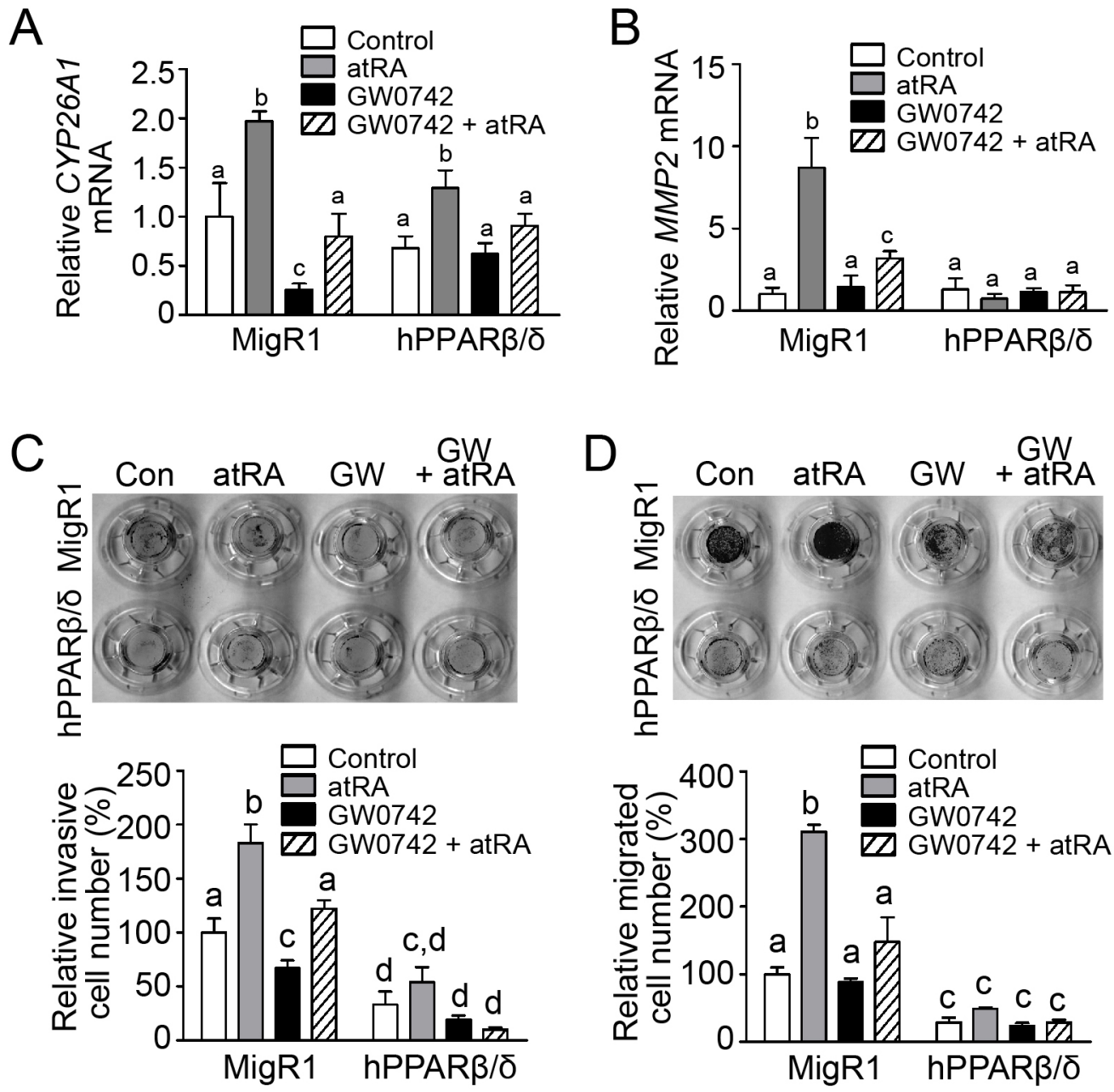

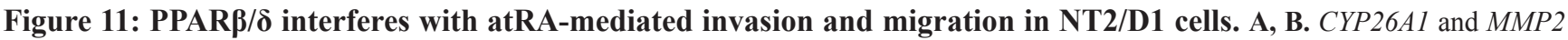
mRNA expression in MigR1 and hPPAR $\beta / \delta$ cells following atRA treatment were determined by qPCR, respectively. C, D. Upper panel, representative photographs of transwell inserts in invasion or migration assay, respectively, in MigR1 or hPPAR $\beta / \delta$ cells in response to atRA and/or GW0742 treatment, and lower panel, quantification of invasive or migrated cells, respectively, normalized to MigR1 control group. Values represent mean \pm S.E.M. Values with different superscript letters are significantly different at $p \leq 0.05$.

MMP-dependent activities [35-37]. Interestingly, specific repression of PPAR $\beta / \delta$-dependent gene expression by an inverse agonist (DG172) inhibits human breast cancer cell invasion [38]. The present study used complementary analysis of migration, invasion and MMP expression and activity and revealed strong evidence supporting the prior experiments showing that PPAR $\beta / \delta$ inhibits MMP-dependent activities in testicular carcinoma cells. While there is similar uncertainty regarding the role of atRA in MMP regulation [20,39-41], results from the present studies also provide strong evidence that RAR can increase MMP2 activity and that increasing expression and activation of PPAR $\beta / \delta$ can inhibit this effect by competing with the heterodimerization partner, RXR, that is used by both RAR and PPAR $\beta / \delta$. The latter represents a highly novel approach that may be useful for preventing/treating human testicular cancer or other cancers. The utility of increasing PPAR $\beta / \delta$ expression to inhibit RAR-dependent expression of MMP2 and its activity may be feasible since ligand activation of PPAR $\beta / \delta$ can increase expression of $\operatorname{PPAR} \beta / \delta$, possibly through a positive feedback loop [7, 42]. Over-expression of PPAR $\beta / \delta$ did not alter expression of either RXR $\alpha$ or RAR $\alpha$ in NT2/D1 cells. However, the expression of CRABPII, a protein involved in the transport of atRA was significantly reduced in NT2/ D1-hPPAR $\beta / \delta$ cells. The change in CRABPII expression by PPAR $\beta / \delta$ represents another novel mechanism by which $P P A R \beta / \delta$ may interfere with RAR-dependent MMP signaling. Since atRA caused no change in the FABP5:CRABPII ratio, results from the present study are inconsistent with previous work suggesting that atRA acts as a selective PPAR $\beta / \delta$ agonist [24].

No change in apoptosis was observed in the xenografts in the present study. Further, staurosporineinduced and/or UVB-induced apoptosis was unaffected by ligand activation or over-expression of PPAR $\beta / \delta$. 
Combined, this suggests that $\operatorname{PPAR} \beta / \delta$ has limited effect on regulating apoptosis in testicular embryonal carcinoma cells. However, increased necrosis was observed in xenograft tumors derived from NT2/D1$\mathrm{hPPAR} \beta / \delta$ cells that was associated with suppression of tumor mass. While ligand activation of PPAR $\beta / \delta$ did not further increase the percentage of necrotic area within the tumor, this is likely due to the extremely small size of these tumors. This is also consistent with studies showing that high expression of $\mathrm{PPAR} \beta / \delta$ causes necrosis in colon and breast cancer cell lines $[15,16]$. Thus, there is accumulating evidence that PPAR $\beta / \delta$-induced necrosis may be a common therapeutic/preventive mechanism. Further studies are needed to determine how PPAR $\beta / \delta$ regulates necrosis.

Results from this present study demonstrate that $\operatorname{PPAR} \beta / \delta$ attenuates tumor progression in testicular embryonal carcinoma, in part, through interfering with RAR $\alpha$ signaling and suppressing MMP2-mediated cell invasion and migration. Whether this regulation is limited in testicular cancer cells or is a common mechanism in other cancer cells remains uncertain. Further detailed investigations are required to examine this idea. This study suggests that specific modulation of RAR $\alpha$ signaling may be a viable approach for the treatment of testicular germ cell tumors.

\section{MATERIALS AND METHODS}

\section{Cell lines}

The human testicular embryonal carcinoma cell lines, NTERA-2 cl. D1 (NT2/D1) and Tera2 were purchased from American Type Culture Collection (ATCC, Manassas, VA) in February 2012. The NT2/D1 cells were cultured in Dulbecco's modified Eagle's media (DMEM, Cellgro, Manassas, VA) supplemented with 10\% fetal bovine serum (FBS) and 1\% penicillin-streptomycin (Invitrogen, Grand Island, NY) at $37^{\circ} \mathrm{C}$ with $5 \%$ carbon dioxide. Tera2 cells were cultured in McCoy's 5A Medium (Lonza Inc., Williamsport, PA) supplemented with $15 \% \mathrm{FBS}$ and $1 \%$ penicillin-streptomycin (Invitrogen, Grand Island, NY) at $37^{\circ} \mathrm{C}$ with $5 \%$ carbon dioxide. The morphology of the cells was consistent with the description provided by ATCC and low passage cells were used for all experiments. ATCC uses multiple approaches to authenticate human cell lines and to rule out both intraand interspecies contamination.

\section{Stable human testicular embryonal carcinoma

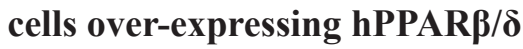

A stable human PPAR $\beta / \delta$ (hPPAR $\beta / \delta)$ overexpressing NT2/D1 or cell line was produced using a bi-cistronic retroviral vector (MigR1-eGFP) encoding the human PPAR $\beta / \delta$ cDNA and eGFP that was transduced into NT2/D1 cells as previously described [15]. $1 \times 10^{4}$ control NT2/D1 cells with stably integrated MigR1-eGFP (NT2/D1-MigR1) or NT2/D1 cells overexpressing the bi-cistronic MigR1-eGFP-hPPAR $\beta / \delta$ vector $(\mathrm{NT} 2 / \mathrm{D} 1-\mathrm{hPPAR} \beta / \delta)$ were seeded on 4 -well chamber slides (Thermo Scientific, Waltham, MA) and mounted in Vectashield Mounting Medium containing propidium iodide (PI) (Vector Labs, Burlingame, CA). Cells were imaged using Olympus FV1000 laser scanning confocal microscope (Olympus America Inc., Melville, NY) to detect eGFP and PI signals with excitation/emission wavelengths of 499/519 $\mathrm{nm}$ and $652 / 668 \mathrm{~nm}$, respectively. Cells were treated with or without GW0742 (a specific PPAR $\beta / \delta$ agonist [43]), GSK3787 (a specific PPAR $\beta / \delta$ antagonist [44]), or SB3CT (a specific gelatinase inhibitor [45]). GW0742 and GSK3787 were kindly provided by Drs. Andrew Billin and Timothy Willson (GlaxoSmithKline, Research Triangle Park, NC) and SB-3CT was purchased (SigmaAldrich. St. Louis, MO).

A similar strategy using retroviral transduction described for the NT2/D1 cells was performed to generate stable Tera 2 cell line over-expressing PPAR $\beta / \delta$.

\section{Western blot analysis}

Quantitative western blot analysis using a radioactive detection method was performed as previously described [15]. Primary antibodies used included proliferating cell nuclear antigen (PCNA), RXR $\alpha, R A R \alpha$, ACTIN (Santa Cruz Biotechnology, Santa Cruz, CA), cellular retinoic acid-binding protein II (CRABPII), cytochrome P450 26A1 (CYP26A1), PPAR $\beta / \delta$ (Abcam, Cambridge, MA), octamer-binding transcription factor 3/4 (OCT3/4; Cell Signaling Technology, Danvers, MA), fatty acid binding protein 5 (FABP5; BioVedor Inc., Asheville, NC) and lactate dehydrogenase (LDH; Rockland, Gilbertsville, PA), The expression level of each protein was normalized to LDH or ACTIN.

\section{Quantitative real-time polymerase chain reaction (qPCR)}

Expression of target genes in NT2/D1 cells was determined by qPCR analysis as previously described [15]. The forward and reverse primers, respectively, were: angiopoietin-like protein 4 (ANGPTL4, NM_139314) 5'TCA CAG CCT GCA GAC ACA ACT CAA-3' and 5'CCA AAC TGG CTT TGC AGA TGC TGA-3'; OCT3/4 (NM 002701): 5'- CCT GAA GCA GAA GAG GAT CA-3' and 5'-CCG CAG CTT ACA CAT GTT CT-3'; CYP26A1 (NM_000783): 5'-TTC TGC AGA TGA AGC GCA GG - $3^{\prime}$ and 5'-TTT CGC TGC TTG TGC GAG GA -3'; MMP2 (NM_004530): 5'-GGA CAC ACT AAA GAA GAT GCA GAA G-3' and 5'-CGC ATG GTC TCG ATG GTA TTC-3'; glyceraldehyde-3-phosphate dehydrogenase 
(GAPDH, NM_002046): 5'-TGC ACC ACC ACC TGC TTA GC-3' and 5'-GGC ATG GAC TGT GGT CAT GAG-3'. Each assay included a standard curve and a non-template control that were performed in triplicate. Relative mRNA levels of target genes were normalized to the mRNA level of GAPDH.

\section{Cell proliferation assay}

The xCELLigence system (ACEA Biosciences, Inc. San Diego, CA) was used for determining the changes in real-time cell proliferation in NT2/D1 and Tera2 cells as previously described [15].

\section{Anchorage-dependent and anchorage- independent cell growth}

Anchorage-dependent clonogenicity of NT2/D1, NT2/D2-MigR1 and NT2/D1-hPPAR $\beta / \delta$ cells ( 800 cells/ dish) with and without ligand activation of PPAR $\beta / \delta$ agonist was determined as previously described [15]. The plating efficiency and surviving fraction were calculated after 14 days of plating as previously described [46]. Anchorage-independent cell growth of NT2/D1-MigR1 and NT2/D1-hPPAR $\beta / \delta$ cells $(7,500$ cells/dish) on $0.5 \%$ base agar and $0.35 \%$ top agarose with and without ligand activation of $\mathrm{PPAR} \beta / \delta$ were assessed as previously described [47]. Cell colony numbers were counted after 12 days of plating, and the diameter and surface area of colonies were determined by ImageJ software (Version 1.47c; National Institutes of Health, Bethesda, MD).

\section{Gelatin zymography}

Since MMP activity promotes anchorageindependent transformation [19], gelatinolytic activities of MMP2 and MMP9 in serum-free media collected from NT2/D1, NT2/D1-MigR1 or NT2/D1-hPPAR $\beta / \delta$ cells in response to a PPAR $\beta / \delta$ agonist (GW0742), or a PPAR $\beta / \delta$ antagonist (GSK3787) were assessed by gelatin zymography as previously described [48]. The relative gelatinolytic activities of pro-MMP2, MMP2 and proMMP9 were determined using ImageJ software (Version 1.47c; National Institutes of Health, Bethesda, MD).

\section{Ectopic xenograft tumor assay}

Tumor growth of xenografts derived from NT2/ D1-MigR1 and NT2/D1-hPPAR $\beta / \delta$ cells $\left(5 \times 10^{6}\right)$ were assessed using 6-week-old female immunodeficient athymic nude (nu/nu) mice (Frederick National Laboratory for Cancer Research, Frederick, MD) as previously described [15]. Groups of mice $(n=10)$ were treated with either vehicle control $(0.02 \%$ dimethylsulfoxide $)$ or GW0742 (2.5 mg/kg/day) for up to 40 days. At the end of this treatment period, mice were euthanized and tumors excised, weighed, sections were fixed in $10 \%$ phosphate buffered formalin overnight and then switched to $75 \%$ ethanol. A separate section was snap frozen in liquid nitrogen for protein or mRNA analysis. Fixed tumor sections were processed for staining as previously described [15]. Hematoxylin-eosin (H\&E) stained tumor sections were examined by a pathologist.

\section{Immunohistochemistry}

Expression and localization of PCNA and OCT3/4 in ectopic xenograft tumors were determined by immunohistochemistry using 3,3'-diaminobenzidine (DAB) as a substrate and counterstained by hematoxylin as previously described [49]. Twenty fields per sections and two sections per tumor sample were analyzed. Relative expression was determined by normalizing the intensity of DAB to hematoxylin signals using ImageJ software (Version 1.47c).

\section{Terminal deoxy-nucleotidyl transferase- mediated digoxigenin-dUTP nick end labeling (TUNEL) assay}

Apoptotic fragmentation of DNA in paraffinembedded tumor sections was determined using the ApopTag $^{\text {TM }}$ kit (Chemicon, Temecula, CA) following the manufacturer's instructions. Twenty fields per sections and two sections per tumor sample were analyzed. The relative level of apoptosis was determined by normalizing the intensity of DAB to hematoxylin signals using ImageJ software (Version $1.47 \mathrm{c}$ ).

\section{Invasion of endothelial cell monolayer by testicular cancer cells}

The initial step of metastasis involves the degradation of basement membrane and invasion through vascular endothelial cells [50]. Therefore, the interaction between tumor cells and endothelia cells can be an indicator of cell invasion. To determine whether over-expression and/or activation of PPAR $\beta / \delta$ influenced cell invasion, the interaction between NT2/D1 cell lines and human umbilical vein endothelial cells (HUVEC, purchased from ATCC) was monitored in real-time using xCELLigence as previously described [51]. HUVEC cells $\left(2.5 \times 10^{4}\right)$ were seeded on E-plates to form a monolayer, and NT2/D1 cell lines $\left(1 \times 10^{4}\right)$ were seeded on top of HUVEC monolayer. Testicular embryonal carcinoma cell invasion of HUVEC monolayer was recorded up to 8 hours. Cell index was altered due to the disruption of HUVEC monolayer by the invading testicular cancer cells. 


\section{Invasion assay}

The transwell invasion assay was performed as previously described [48]. After 48 hours, cells attached to the lower surface of transwell inserts were counted using a light microscope with 200X magnification. Real-time cell invasion in NT2/D1 cells was also performed using the xCELLigence system following the manufacturer's protocol.

\section{Migration assay}

The transwell migration assay and the woundhealing assay were performed as previously described $[48,52]$. After 48 hours, cells attached to the lower surface of the transwell inserts were counted using a light microscope with 200X magnification. Relative wound closure was determined using the wound-healing assay and was calculated with the following formula (initial width $(\sim 0.6 \mathrm{~mm})$ minus end width after $48 \mathrm{~h}$ of culture)/ (initial width $(\sim 0.6 \mathrm{~mm})) \mathrm{X} 100$. Real-time cell migration in NT2/D1 cells was also performed using xCELLigence following the manufacturer's protocol.

\section{Electrophoretic mobility shift assay (EMSA)}

A putative RAR response element (RE) was identified in the human $M M P 2$ promoter using the PROMO program [53]. Oligonucleotides containing the RAR binding sequence designed for EMSA are shown in Table 1. The binding pattern of endogenous RAR from NT2/D1-MigR1 and NT2/D1-hPPAR $\beta / \delta$ cells to the putative RE was determined by non-radioactive electrophoretic mobility shift assay as previously described [54] and analyzed using a gel imaging system (Bio-Rad Laboratories, Inc., Hercules, CA). A super shift assay was performed by adding a primary antibody against
RAR $\alpha$ to the protein-DNA complexes and incubated at $4^{\circ} \mathrm{C}$ for additional $30 \mathrm{~min}$.

\section{Transient over-expression and activation of RAR $\alpha$ in NT2/D1 cells}

NT2/D1, NT2/D1-MigR1 and NT2/D1-hPPAR $\beta / \delta$ $\left(5 \times 10^{5}\right)$ were transiently transfected with $10 \mu \mathrm{g}$ of a pSG5-RAR $\alpha$ plasmid using Lipofectamine LTX reagent (Invitrogen, Grand Island, NY) following the manufacturer's recommended procedures. Transfected cells were treated with or without $10 \mu \mathrm{M}$ all-trans retinoic acid (atRA, a specific RAR agonist, Sigma-Aldrich, St. Louis, MO) for 24 hours. Over-expression of RAR $\alpha$ was confirmed by quantitative western blot analysis, and the expression of the RAR target gene CYP26A1 was determined by qPCR.

\section{Chromatin immunoprecipitation (ChIP)}

The occupancy of RAR on the $M M P 2$ promoter in response to over-expression and/or activation of $\operatorname{PPAR} \beta / \delta$, or over-expression and/or activation of RAR $\alpha$ was determined by ChIP as previously described [7]. Antibodies against RAR $\alpha$, progesterone receptor (PR), and normal rabbit-IgG (Santa Cruz Biotechnology, Santa Cruz, CA) were individually added to histone-DNA complexes for immunoprecipitation of protein bound chromatin. The antibody against PR, which did not bind to $M M P 2$ promoter, and rabbit-IgG were used as negative controls. The chromatin fragments were amplified by PCR (26 cycles) using primers flanking the putative RAR $\alpha$ binding sequence in $M M P 2$ promoter shown in Table 1, and resolved on $2 \%$ agarose gels. ChIP-qPCR was also performed to quantify relative promoter occupancy. The relative level of RAR-occupied $M M P 2$ promoter in each group was normalized to input control.

\section{Table 1: Oligonucleotide sequences for EMSA, ChIP and ChIP-qPCR}

\begin{tabular}{l}
\hline Name \\
\begin{tabular}{|l|c|}
\hline EMSA & Sequence $\left(\mathbf{5}^{\prime} \mathbf{\otimes} \mathbf{3}^{\prime}\right)$ \\
\hline Wild-type oligonucleotide & ctgacccccagtcctatctgcc \\
\hline MMP2-F291 & ggcagataggactgggggtcag \\
\hline MMP2-R269 & ctgaccTTcagtcetatctgcc \\
\hline Mutant oligonucleotide (capitalized) & ggcagataggactgAAggtcag \\
\hline$\triangle$ MMP2-F291 & \\
\hline$\triangle M M P 2-R 269$ & tcctaggctggtcctcactg \\
\hline ChIP, ChIP-qPCR & gaggcactggagaagaaagt \\
\hline MMP2-F266 & \\
\hline MMP2-R173 & \\
\hline
\end{tabular}
\end{tabular}




\section{Statistical analyses}

All experimental groups were performed in triplicate and repeated using three independent biological replicates. The data were subjected to Student's $t$-test or a parametric one-way analysis of variance (ANOVA) followed by Tukey test for post hoc comparisons. Statistical significance was considered to be achieved when $p \leq 0.05$.

\section{ACKNOWLEDGMENTS AND FUNDING}

The authors gratefully thank the Microscopy and Cytometry Facility at the Huck Institute of Life Sciences of The Pennsylvania State University for providing technique support with flow cytometer, histology equipment and confocal microscope.

\section{CONFLICTS OF INTEREST}

All authors have no perceived conflicts of interest to disclose.

\section{GRANT SUPPORT}

This study was supported by the National Institutes of Health and National Cancer Institute grants R01CA124533 (J. M. Peters), R01-CA141029 (J.M. Peters), 1ZIABC005561 (F.J. Gonzalez), 1ZIABC005562 (F.J. Gonzalez), and 1ZIABC005708 (F.J. Gonzalez).

\section{REFERENCES}

1. Holmes L Jr., Escalante C, Garrison O, Foldi BX, Ogungbade GO, Essien EJ, Ward D. Testicular cancer incidence trends in the USA (1975-2004): plateau or shifting racial paradigm? Public Health. 2008; 122:862-872.

2. Osswald M, Harlan LC, Penson D, Stevens JL, Clegg LX. Treatment of a population based sample of men diagnosed with testicular cancer in the United States. Urologic oncology. 2009; 27:604-610.

3. Voutsadakis IA. The chemosensitivity of testicular germ cell tumors. Cellular oncology. 2014; 37:79-94.

4. Boublikova L, Buchler T, Stary J, Abrahamova J, Trka J. Molecular biology of testicular germ cell tumors: unique features awaiting clinical application. Critical reviews in oncology/hematology. 2014; 89:366-385.

5. Bahrami A, Ro JY, Ayala AG. An overview of testicular germ cell tumors. Archives of pathology \& laboratory medicine. 2007; 131:1267-1280

6. Skakkebaek NE, Rajpert-De Meyts E, Main KM. Testicular dysgenesis syndrome: an increasingly common developmental disorder with environmental aspects. Hum Reprod. 2001; 16:972-978.
7. Khozoie C, Borland MG, Zhu B, Baek S, John S, Hager GL, Shah YM, Gonzalez FJ, Peters JM. Analysis of the peroxisome proliferator-activated receptor- $\beta / \delta(\operatorname{PPAR} \beta / \delta)$ cistrome reveals novel co-regulatory role of ATF4. BMC genomics. 2012; 13:665.

8. Peters JM, Shah YM, Gonzalez FJ. The role of peroxisome proliferator-activated receptors in carcinogenesis and chemoprevention. Nature reviews. 2012; 12:181-195.

9. Orlov I, Rochel N, Moras D, Klaholz BP. Structure of the full human RXR/VDR nuclear receptor heterodimer complex with its DR3 target DNA. The EMBO journal. 2012; 31:291-300.

10. Rastinejad F, Wagner T, Zhao Q, Khorasanizadeh S. Structure of the RXR-RAR DNA-binding complex on the retinoic acid response element DR1. The EMBO journal. 2000; 19:1045-1054.

11. Li D, Li T, Wang F, Tian H, Samuels HH. Functional evidence for retinoid $\mathrm{X}$ receptor (RXR) as a nonsilent partner in the thyroid hormone receptor/RXR heterodimer. Molecular and cellular biology. 2002; 22:5782-5792.

12. Chan LS, Wells RA. Cross-Talk between PPARs and the Partners of RXR: A Molecular Perspective. PPAR research. 2009; 2009:925309.

13. DiRenzo J, Soderstrom M, Kurokawa R, Ogliastro MH, Ricote M, Ingrey S, Horlein A, Rosenfeld MG, Glass CK. Peroxisome proliferator-activated receptors and retinoic acid receptors differentially control the interactions of retinoid X receptor heterodimers with ligands, coactivators, and corepressors. Molecular and cellular biology. 1997; 17:2166-2176.

14. Lu C, Cheng SY. Thyroid hormone receptors regulate adipogenesis and carcinogenesis via crosstalk signaling with peroxisome proliferator-activated receptors. Journal of molecular endocrinology. 2010; 44:143-154.

15. Yao PL, Morales JL, Zhu B, Kang BH, Gonzalez FJ, Peters JM. Activation of peroxisome proliferator-activated receptor- $\beta / \delta$ (PPAR- $\beta / \delta$ ) inhibits human breast cancer cell line tumorigenicity. Molecular cancer therapeutics. 2014; 13:1008-1017.

16. Foreman JE, Chang WC, Palkar PS, Zhu B, Borland MG, Williams JL, Kramer LR, Clapper ML, Gonzalez FJ, Peters JM. Functional characterization of peroxisome proliferator-activated receptor- $\beta / \delta$ expression in colon cancer. Molecular carcinogenesis. 2011; 50:884-900.

17. Zhu B, Bai R, Kennett MJ, Kang BH, Gonzalez FJ, Peters JM. Chemoprevention of chemically induced skin tumorigenesis by ligand activation of peroxisome proliferator-activated receptor- $\beta / \delta$ and inhibition of cyclooxygenase 2 . Molecular cancer therapeutics. 2010; 9:3267-3277.

18. Uhlen M, Fagerberg L, Hallstrom BM, Lindskog C, Oksvold P, Mardinoglu A, Sivertsson A, Kampf C, Sjostedt E, Asplund A, Olsson I, Edlund K, Lundberg E, et al. 
Proteomics. Tissue-based map of the human proteome. Science. 2015; 347:1260419.

19. Hillion J, Wood LJ, Mukherjee M, Bhattacharya R, Di Cello F, Kowalski J, Elbahloul O, Segal J, Poirier J, Rudin CM, Dhara S, Belton A, Joseph B, Zucker S, Resar LM. Upregulation of MMP-2 by HMGA1 promotes transformation in undifferentiated, large-cell lung cancer. Molecular cancer research : MCR. 2009; 7:1803-1812.

20. Dutta A, Sen T, Banerji A, Das S, Chatterjee A. Studies on Multifunctional Effect of All-Trans Retinoic Acid (ATRA) on Matrix Metalloproteinase-2 (MMP-2) and Its Regulatory Molecules in Human Breast Cancer Cells (MCF-7). Journal of oncology. 2009; 2009:627840.

21. Kim JM, Kang SW, Shin SM, Su Kim D, Choi KK, Kim EC, Kim SY. Inhibition of matrix metalloproteinases expression in human dental pulp cells by all-trans retinoic acid. Int J Oral Sci. 2014; 6:150-153.

22. Lei FY, Zhou TB, Qin YH, Chen XP, Li ZY. Potential signal pathway of all-trans retinoic acid for MMP-2 and MMP-9 expression in injury podocyte induced by adriamycin. J Recept Signal Transduct Res. 2014; 34:378-385.

23. Wang H, Dan Z, Jiang H. Effect of all-trans retinoic acid on liver fibrosis induced by common bile duct ligation in rats. J Huazhong Univ Sci Technolog Med Sci. 2008; 28:553-557.

24. Schug TT, Berry DC, Shaw NS, Travis SN, Noy N. Opposing effects of retinoic acid on cell growth result from alternate activation of two different nuclear receptors. Cell. 2007; 129:723-733.

25. Kristensen DM, Sonne SB, Ottesen AM, Perrett RM, Nielsen JE, Almstrup K, Skakkebaek NE, Leffers H, Rajpert-De Meyts E. Origin of pluripotent germ cell tumours: the role of microenvironment during embryonic development. Molecular and cellular endocrinology. 2008; 288:111-118.

26. Niwa H, Miyazaki J, Smith AG. Quantitative expression of Oct-3/4 defines differentiation, dedifferentiation or selfrenewal of ES cells. Nature genetics. 2000; 24:372-376.

27. Buttitta LA, Edgar BA. Mechanisms controlling cell cycle exit upon terminal differentiation. Curr Opin Cell Biol. 2007; 19:697-704.

28. Andrews PW, Damjanov I, Simon D, Banting GS, Carlin C, Dracopoli NC, Fogh J. Pluripotent embryonal carcinoma clones derived from the human teratocarcinoma cell line Tera-2. Differentiation in vivo and in vitro. Lab Invest. 1984; 50:147-162.

29. Przyborski SA. Isolation of human embryonal carcinoma stem cells by immunomagnetic sorting. Stem Cells. 2001; 19:500-504.

30. Andrews PW. Retinoic acid induces neuronal differentiation of a cloned human embryonal carcinoma cell line in vitro. Dev Biol. 1984; 103:285-293.

31. Pleasure SJ, Lee VM. NTera 2 cells: a human cell line which displays characteristics expected of a human committed neuronal progenitor cell. J Neurosci Res. 1993; 35:585-602.

32. Cheung HH, Davis AJ, Lee TL, Pang AL, Nagrani S, Rennert OM, Chan WY. Methylation of an intronic region regulates miR-199a in testicular tumor malignancy. Oncogene. 2011; 30:3404-3415.

33. Ham SA, Yoo T, Hwang JS, Kang ES, Lee WJ, Paek KS, Park C, Kim JH, Do JT, Lim DS, Seo HG. Ligand-activated PPAR $\delta$ modulates the migration and invasion of melanoma cells by regulating Snail expression. American journal of cancer research. 2014; 4:674-682.

34. Pollock CB, Rodriguez O, Martin PL, Albanese C, Li X, Kopelovich L, Glazer RI. Induction of metastatic gastric cancer by peroxisome proliferator-activated receptor- $\delta$ activation. PPAR research. 2010; 2010:571783.

35. Barlaka E, Gorbe A, Gaspar R, Paloczi J, Ferdinandy P, Lazou A. Activation of PPAR $\beta / \delta$ protects cardiac myocytes from oxidative stress-induced apoptosis by suppressing generation of reactive oxygen/nitrogen species and expression of matrix metalloproteinases. Pharmacol Res. 2015; 95-96C:102-110.

36. Coleman JD, Thompson JT, Smith RW 3rd, Prokopczyk B, Vanden Heuvel JP. Role of Peroxisome ProliferatorActivated Receptor $\beta / \delta$ and B-Cell Lymphoma-6 in Regulation of Genes Involved in Metastasis and Migration in Pancreatic Cancer Cells. PPAR research. 2013; 2013:121956.

37. Ham SA, Yoo T, Hwang JS, Kang ES, Paek KS, Park C, Kim JH, Do JT, Seo HG. Peroxisome proliferatoractivated receptor $\delta$ modulates MMP-2 secretion and elastin expression in human dermal fibroblasts exposed to ultraviolet B radiation. J Dermatol Sci. 2014; 76:44-50.

38. Adhikary T, Brandt DT, Kaddatz K, Stockert J, Naruhn S, Meissner W, Finkernagel F, Obert J, Lieber S, Scharfe M, Jarek M, Toth PM, Scheer F, et al. Inverse PPAR $\beta / \delta$ agonists suppress oncogenic signaling to the ANGPTL4 gene and inhibit cancer cell invasion. Oncogene. 2013; 32:5241-5252.

39. Dalmolin RJ, Zanotto-Filho A, De Oliveira RB, Duarte RF, Pasquali MA, Moreira JC. Retinol and retinoic acid increase MMP-2 activity by different pathways in cultured Sertoli cells. Free radical research. 2007; 41:1338-1347.

40. Frankenberger M, Hauck RW, Frankenberger B, Haussinger K, Maier KL, Heyder J, Ziegler-Heitbrock HW. All trans-retinoic acid selectively down-regulates matrix metalloproteinase-9 (MMP-9) and up-regulates tissue inhibitor of metalloproteinase-1 (TIMP-1) in human bronchoalveolar lavage cells. Molecular medicine. 2001; 7:263-270.

41. Joshi S, Guleria RS, Pan J, Dipette D, Singh US. Heterogeneity in retinoic acid signaling in neuroblastomas: Role of matrix metalloproteinases in retinoic acid-induced differentiation. Biochimica et biophysica acta. 2007; 1772:1093-1102.

42. Ogata M, Tsujita M, Hossain MA, Akita N, Gonzalez FJ, Staels B, Suzuki S, Fukutomi T, Kimura G, Yokoyama S. 
On the mechanism for PPAR agonists to enhance ABCA1 gene expression. Atherosclerosis. 2009; 205:413-419.

43. Sznaidman ML, Haffner CD, Maloney PR, Fivush A, Chao E, Goreham D, Sierra ML, LeGrumelec C, Xu HE, Montana VG, Lambert MH, Willson TM, Oliver WR Jr, Sternbach DD. Novel selective small molecule agonists for peroxisome proliferator-activated receptor $\delta$ (PPAR $\delta$ ) synthesis and biological activity. Bioorganic \& medicinal chemistry letters. 2003; 13:1517-1521.

44. Shearer BG, Wiethe RW, Ashe A, Billin AN, Way JM, Stanley TB, Wagner CD, Xu RX, Leesnitzer LM, Merrihew RV, Shearer TW, Jeune MR, Ulrich JC, Willson TM. Identification and characterization of 4-chloro-N-(2-\{[5-trifluoromethyl)-2pyridyl]sulfonyl $\}$ ethyl)benzamide(GSK3787), a selective and irreversible peroxisome proliferator-activated receptor $\delta$ (PPAR $\delta$ ) antagonist. Journal of medicinal chemistry. 2010; 53:1857-1861.

45. Tao P, Fisher JF, Mobashery S, Schlegel HB. DFT studies of the ring-opening mechanism of SB-3CT, a potent inhibitor of matrix metalloproteinase 2. Organic letters. 2009; 11:2559-2562.

46. Foreman JE, Sharma AK, Amin S, Gonzalez FJ, Peters JM. Ligand activation of peroxisome proliferator-activated receptor- $\beta / \delta(\operatorname{PPAR} \beta / \delta)$ inhibits cell growth in a mouse mammary gland cancer cell line. Cancer Lett. 2010; 288:219-225.

47. Kakuguchi W, Kitamura T, Kuroshima T, Ishikawa M, Kitagawa Y, Totsuka Y, Shindoh M, Higashino F. HuR knockdown changes the oncogenic potential of oral cancer cells. Molecular cancer research : MCR. 2010; 8:520-528.
48. Yao PL, Lin YC, Richburg JH. Mono-(2-ethylhexyl) phthalate (MEHP) promotes invasion and migration of human testicular embryonal carcinoma cells. Biology of reproduction. 2012; 86:160, 161-110.

49. Yao PL, Ehresman DJ, Rae JM, Chang SC, Frame SR, Butenhoff JL, Kennedy GL, Peters JM. Comparative in vivo and in vitro analysis of possible estrogenic effects of perfluorooctanoic acid. Toxicology. 2014; 326:62-73.

50. van Zijl F, Krupitza G, Mikulits W. Initial steps of metastasis: cell invasion and endothelial transmigration. Mutation research. 2011; 728:23-34.

51. Rahim S, Uren A. A real-time electrical impedance based technique to measure invasion of endothelial cell monolayer by cancer cells. Journal of visualized experiments : JoVE. 2011.

52. Chen Y, Lu B, Yang Q, Fearns C, Yates JR 3rd, Lee JD. Combined integrin phosphoproteomic analyses and small interfering RNA - based functional screening identify key regulators for cancer cell adhesion and migration. Cancer research. 2009; 69:3713-3720.

53. Messeguer X, Escudero R, Farre D, Nunez O, Martinez J, Alba MM. PROMO: detection of known transcription regulatory elements using species-tailored searches. Bioinformatics. 2002; 18:333-334.

54. Yao PL, Lin YC, Richburg JH. Transcriptional suppression of Sertoli cell Timp2 in rodents following mono-(2ethylhexyl) phthalate exposure is regulated by CEBPA and MYC. Biology of reproduction. 2011; 85:1203-1215. 